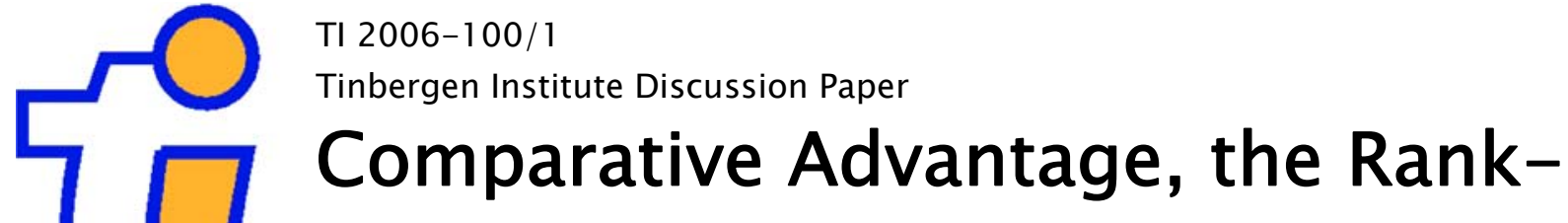 size Rule, and Zipf's Law
}

Jeroen Hinloopen

Charles van Marrewijk ${ }^{2}$

' Universiteit van Amsterdam, and Tinbergen Institute.

2 Erasmus Universiteit Rotterdam. 


\section{Tinbergen Institute}

The Tinbergen Institute is the institute for economic research of the Erasmus Universiteit Rotterdam, Universiteit van Amsterdam, and Vrije Universiteit Amsterdam.

Tinbergen Institute Amsterdam

Roetersstraat 31

1018 WB Amsterdam

The Netherlands

Tel.: $\quad+31(0) 205513500$

Fax: $\quad+31(0) 205513555$

Tinbergen Institute Rotterdam

Burg. Oudlaan 50

3062 PA Rotterdam

The Netherlands

Tel.: $\quad+31(0) 104088900$

Fax: $\quad+31(0) 104089031$

Most TI discussion papers can be downloaded at http:/ /www.tinbergen.nl. 


\title{
Comparative advantage, the rank-size rule, and Zipf's law ${ }^{1}$
}

\author{
Jeroen Hinloopen ${ }^{2}$ \\ Universiteit van Amsterdam and Katholieke Universiteit Leuven \\ Charles van Marrewijk \\ Erasmus Universiteit Rotterdam
}

November 2006

\begin{abstract}
Using a comprehensive international trade data set we investigate empirical regularities (known as Zipf's Law or the rank-size rule) for the distribution of the interaction between countries as measured by revealed comparative advantage. Using the recently developed estimator by Gabaix and Ibragimov (2006) we find strong evidence in favor of the rank-size rule along the time, country, and sector dimension for three different levels of data aggregation. The estimated power exponents that characterize the distribution of revealed comparative advantage are stable over time but differ between countries and sectors. These differences are related empirically to country and sector characteristics, including population size, GDP, and factor intensities.
\end{abstract}

Keywords: Revealed comparative advantage, Balassa index, rank-size rule, Zipf's Law, power law, Pareto distribution

JEL codes: C13, C33, F1, L1, O5, R12

\footnotetext{
${ }^{1}$ Earlier versions of this paper were presented at the workshops "The Economics of Finance and Extremes" (Eurandom, Technical University Eindhoven), "New Regional Economics in Central European Countries" (Institute for Advanced Studies and Oesterreichische Nationalbank, Vienna), "Trade, Factor Movement and Convergence in Transition Economics" (INFER, Kingston University, London), and "Globalization and employment" (Villigst workshop, Germany) and at seminars at the Utrecht School of Economics and the Erasmus School of Economics. We are grateful to Harry Bowen, Xavier Gabaix, Harry Garretsen, Sidney Resnick, Casper de Vries, and the workshop/seminar participants for useful comments and suggestions. The usual disclaimer applies.

${ }^{2}$ Correspondence: University of Amsterdam, FEB/ASE, Roetersstraat 11, 1018 WB Amsterdam, The Netherlands; J.Hinloopen@uva.nl; www.fee.uva.nl/io/jhinloopen.

${ }^{3}$ Correspondence: Erasmus University Rotterdam, Department of Economics, P.O. Box 1738, 3000 DR Rotterdam, The Netherlands; vanmarrewijk@,few.eur.nl; http://people.few.eur.nl/vanmarrewijk.
} 
"No phenomenon is a phenomenon until it is an observed phenomenon"

Niels Bohr

\section{Introduction}

It is often the revelation of empirical regularities that leads to the development of new theories. For instance, Frank Auerbach's observation that city sizes are distributed regularly has led to the development of a body of literature that explains this observed pattern (Nitsch, 2005), the observation by Jan Tinbergen that gravity laws empirically rule international trade patterns initiated a literature that grasps the economics behind the "gravity equation" (Frankel, 1998), and Robert Engle's observation that in many time series the variance changes over time triggered several theories that explain this observed conditional heteroskedasticity (Semmler, 1994).

In this paper a new empirical regularity is documented: the obedience of revealed comparative advantage to the rank-size rule. The notion of revealed comparative advantage was first introduced by Liesner (1958) and operationalized by Balassa (1965) with his concomitant index. The latter is defined as a country's exports in some sector as a fraction of national exports, divided by world exports in that sector as a fraction of world exports. Whenever the Balassa index exceeds unity, a comparative advantage is 'revealed' for the particular country in the particular sector. On average about one third of all sectors display such a revealed comparative advantage, although this percentage varies considerably across countries (Hinloopen and van Marrewijk, 2001).

The rank-size rule holds if a log-linear relationship exists between the value of some phenomenon and its rank in the related sample. In the special case of a slope equal to one the rank-size rule is labeled "Zipf's law", named after the Harvard linguistic professor George Kingsley Zipf (Zipf, 1949). In this paper we carefully document the fact that the rank-size rule applies whenever a comparative advantage is revealed by the Balassa index, and that in a substantial, but minority, of cases Zipf's law holds. Our analysis is based on a comprehensive data set that is obtained by merging two sets obtained from the Center for International Data at the University of California, Davis (see Feenstra et al., 1997, and Feenstra, 2000). It consists in particular of observations on bilateral trade flows for 747 4-digit sectors, 166 countries, covering the years 1970 through 1997, yielding a total of slightly less than 18.4 million positive observations. This allows for a thorough and systematic empirical analysis of the observed phenomenon along three different dimensions: over time, across countries, and across sectors.

Although applications of the rank-size rule abound, this paper deviates from the existing empirical literature in three main respects. First, countries rather than cities are our unit of observation. In this respect we follow Rose (2005) who argues that the size distribution of 
countries is similar to that for cities. ${ }^{4}$ Second, the distribution of the interaction between economic centers rather than the size distribution as such is our focus of analysis. The innovation here is to use the empirical notion of revealed comparative advantage for capturing the interaction between countries rather than the commonly used gravity equation. Third, we use the estimation procedure recently introduced by Gabaix and Ibragimov (2006) for estimating the Pareto exponent in the rank-size rule equation, as this procedure eliminates the bias inherent to traditional estimators.

We find strong evidence in favor of the rank-size rule for international trade flows that reflect a comparative advantage. Although we focus on reporting the estimates of the power exponents of the Balassa index distribution, some further empirical explorations suggest that these exponents are systematically related to country-specific characteristics and that they differ systematically across sectors in case these are grouped according to factor-intensities. Borrowing the words of Rose $(2005$, p. 11), these findings add to what amounts to be "an intriguing puzzle for future theoretical work."

The remainder of the paper is organized as follows. Section 2 briefly reviews the ranksize rule and its application to the Balassa index. Section 3 discusses some estimation issues. Section 4 contains our empirical findings regarding the applicability of the rank-size rule (and, in particular, Zipf's law) to revealed comparative advantage. Section 5 discusses these findings and presents some further empirical explanations. Section 6 concludes.

\section{The rank-size rule and comparative advantage}

The rank-size rule states that the frequency of occurrence of some event $P$ as a function of the concomitant rank $i$ that follows from this frequency is a power-law function: $P_{i} \sim 1 / i^{\phi}$. In case $\phi$ equals one the rank-size rule is referred to as Zipf's law. Phenomena in economics and finance abound which exhibit the implied heavy-tailedness in the data (i.e. $\phi>0$ ), see e.g. Mandelbrot (1963), Janssen and de Vries (1991), Gabaix (1999), Gabaix et al. (2003), Axtel (2001), and Nitsch (2005).

It appears that revealed comparative advantage also complies to the rank-size rule. The concept of revealed comparative advantage is widely used empirically to identify a country's weak and strong export sectors (for recent applications see e.g. Porter (1990), Amiti (1999), Fertö and Hubbard (2003), or Svaleryd and Vlachos, 2005). In particular, let $X_{i, t}^{j}$ be the value of exports from country $i \in I$ for sector $j \in J$ in period $t \in T$. Then $X_{i, t}=\sum_{j} X_{i, t}^{j}$ is the value of exports from country $i$ in period $t, X_{t}^{j}=\sum_{i} X_{i, t}^{j}$ is the total value of exports for

\footnotetext{
${ }^{4}$ See also Okuyama, Takayasu, and Takayasu (1999) and Axtell (2001) for similar evidence regarding firm size distributions.
} 
sector $j$ in period $t, X_{t}=\sum_{i} \sum_{j} X_{i, t}^{j}$ is the total value of exports for all countries and sectors in that period, and the Balassa index for country $i$ and sector $j$ in period $t$ is defined as:

$$
B_{i, t}^{j}=\frac{X_{i, t}^{j} / X_{i, t}}{X_{t}^{j} / X_{t}}, \quad i \in I, j \in J, t \in T .
$$

If $B_{i, t}^{j}>1$, country $i$ is said to have a revealed comparative advantage in the production of commodity $j$ in time period $t$ as its export share for product $j$ is larger than the concomitant export share in the group of reference countries $I .{ }^{5}$

Figure 1. Empirical relation between the Balassa index of revealed comparative advantage and the related rank.

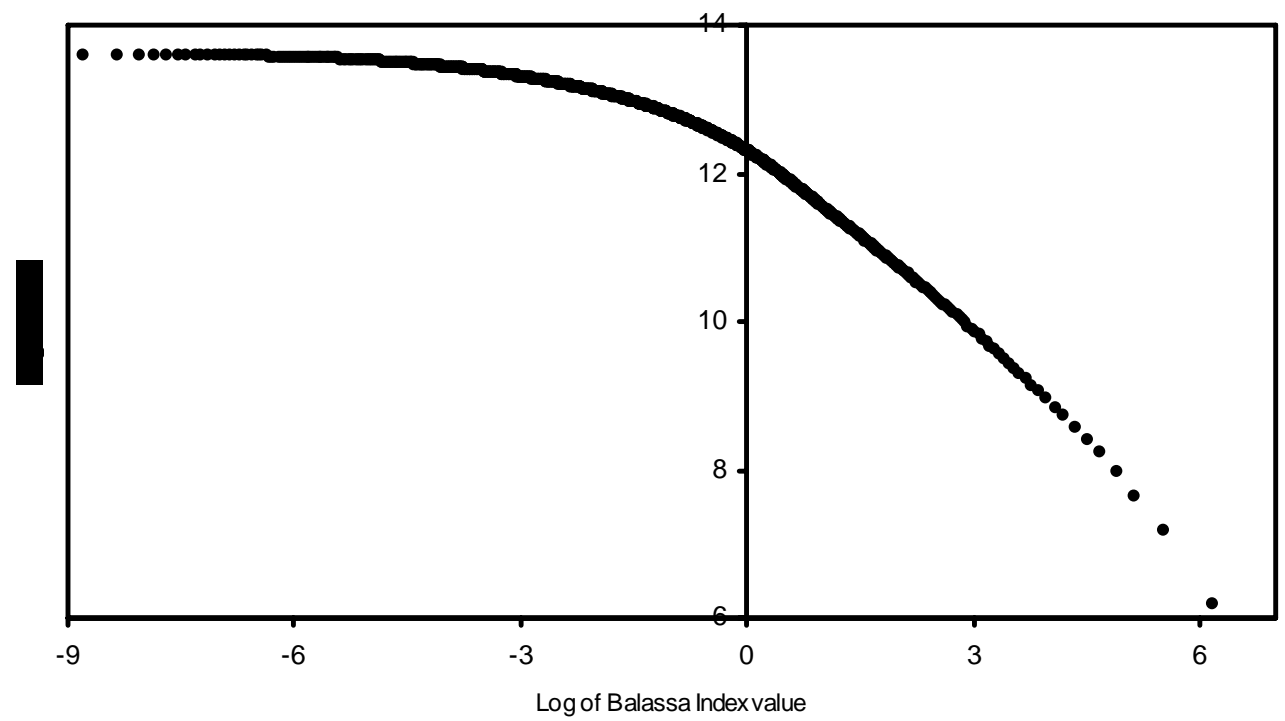

In Figure 1 the log of the Balassa index is plotted against the log of the concomitant rank (the figure is constructed using a random sample of 1,000 observations; appendix A contains the description of the data used throughout the paper), whereby the largest Balassa index value is given rank 1. This picture serves as a first illustration that the rank-size rule applies to the upper tail of the empirical distribution of Balassa index values. Indeed, observations with a Balassa index above unity are grouped almost perfectly on a straight line. It is precisely these observations that reveal a comparative advantage.

\footnotetext{
${ }^{5}$ Hillman (1980) identifies a sufficient condition for the Balassa index to measure comparative advantage proper in that an increase in exports yields an increase in the Balassa index. Throughout the paper the analysis is restricted to those observations that meet this "Hillman condition", which amounts to disgarding $0.25 \%$ of all observations (see Hinloopen and Van Marrewijk (2006) for further details).
} 
Whether or not Zipf's law holds in particular has been of interest in the related literature on city size distributions. Meanwhile the applicability of the rank-size rule to city-size distributions is undisputed but to date there is no agreement as to the particular validity of Zipf's law. Some argue that the power exponent does not assume unity quite regularly (Rosen and Resnick (1980), Brakman, Garretsen, and van Marrewijk (2001), and Soo, 2005), others stress that in most studies the hypothesis that the estimated power exponent equals one cannot be rejected (Krugman (1996), Gabaix (1999), and Gabaix and Ioannides, 2004). Given the scope of our dataset we are quite confident that our findings regarding the applicability of the rank-size rule and, in particular, Zipf's law, to revealed comparative advantage, are representative for the underlying mechanisms.

\section{Estimating a power-law coefficient}

The two most commonly used methods for estimating the power law exponent $\phi$ are OLS (often referred to as the Zipf regression) and employing the Hill estimator (Hill (1975), see also Gabaix and Ioannides, 2004). For large sample sizes the estimated power law coefficient in the Zipf regression tends with probability one to the true value of $\phi$. For small samples, however, the estimate is biased and inefficient. Moreover, the reported standard errors grossly underestimate the true standard errors. Alternatively, under the null hypothesis of a perfect power law, the Hill estimator is the maximum likelihood estimator of $\phi$. But the properties of the Hill estimator in finite samples are also worrisome as the bias can be very high in small samples and the associated computed standard errors considerably underestimate the true standard errors as a result of this bias. As the rate of convergence can be arbitrary slow (Embrechts et al., 1997) the estimator also requires very large samples sizes. Moreover, the choice as to the number of order statistics to be included is problematic in view of the bias variance tradeoff (see Beirlant et al. (2004) and the citations therein).

Various estimators have been developed to address these issues, but these have not led to a consensus solution of the problem (see e.g. Embrechts et al., 1997, Beirlant et al., 1999, and Feuerverger and Hall, 1999). Recently however Gabaix and Ibragimov (2006) provide an elegant and effective solution for the estimation of power exponents: an unbiased estimate is obtained when using OLS in:

$$
\ln \left(\operatorname{rank}-\frac{1}{2}\right)=a-b \ln (\text { size }) \text {. }
$$

Accordingly, all that is needed is to shift the rank by $1 / 2$. Gabaix and Ibragimov (2006) show further that the standard error of the so-estimated power exponent is asymptotically equal to $\sqrt{(2 / n)} b$. Also, using OLS in (2) is more robust to deviations from the exact power law 
formulation (in the sense of Hall, 1982) than is the Hill estimator (see also Ibragimov and Phillips (2004), and Phillips, 2007).

However, given that routine data typically carry up to 10 percent contamination (Hampel et al., 1986) OLS estimates in (2) are likely to be biased. This calls for including as many observations as possible as Gabaix and Ibragimov (2006) show that this bias is inversely related with the sample size. Accordingly, we employ as low as possible a cut-off value for identifying sectors with a revealed comparative advantage. That is, include all observations with a Balassa index of at least one. By doing so we also split the sample at a theoretically meaningful point: include all observations that relate to a revealed comparative advantage.

In sum, we report only the Gabaix-Ibragimov estimates and their associated standard errors for all observations that reveal a comparative advantage. ${ }^{6}$

\section{Empirical results}

Since the Balassa index carries three dimensions (time, country, and sector), we can empirically investigate the size of the power law exponent for these three dimensions. Zipf's law is said to apply in the particular dimension if the estimated slope coefficient of equation (2) does not differ significantly from unity; in all other cases the rank-size rule is said to apply given that the estimated coefficient is statistically significant. Observe that there is a subdimension for the Balassa index with respect to the degree of data aggregation. After eliminating erroneously classified observations, our data set effectively distinguishes 662 digit sectors, 225 3-digit sectors, and 419 4-digit sectors (see Appendix A). ${ }^{7}$ All three identified dimensions are thus considered at three different levels of data aggregation.

\subsection{Dimension I: time}

To examine the applicability of the rank-size rule along the time dimension of revealed comparative advantage the following equation is estimated for all Balassa index values above unity:

$$
\ln \left[\operatorname{rank}\left(B I_{i, t}^{j}\right)-\frac{1}{2}\right]=\alpha_{0, t}+\alpha_{1, t} \ln \left[B I_{i, t}^{j}\right], \quad t=1970, \cdots, 1997 .
$$

Table 1 contains the summary statistics for the several per-year estimates (details of the estimates for all individual years are listed in Table B1 in Appendix B), and the pooled regression whereby all years are taken together. The estimated power exponents vary little per

\footnotetext{
${ }^{6}$ In all cases we also calculated the Zipf regression and the Hill estimator. These are available from the authors upon request.

${ }^{7}$ To be included an observation (i) has a related export value of at least 5,000 US \$, (ii) meets the Hillman condition, and (iii) is at least one. Further, regressions with 10 or fewer observations were dismissed. The smallest number of observations for any regression is 47 .
} 
year and the goodness-of-fit is very high. At the 3-digit level, for example, the estimates range from 0.896 to 0.981 and the goodness-of-fit is between 98.3 and 99.4 per cent.

Table 1. Pooled Gabaix-Ibragimov regression of the slope parameter in (3) and summary statistics based on the 28 concomitant per-year estimates.

\begin{tabular}{lrrr}
\hline \hline & 2-digit & 3-digit & 4-digit \\
\hline average & 0.958 & 0.930 & 0.870 \\
median & 0.949 & 0.922 & 0.860 \\
variance & 0.002 & 0.001 & 0.000 \\
$\min$ & 0.882 & 0.896 & 0.849 \\
$\max$ & 1.031 & 0.981 & 0.915 \\
average \# observations & 1,911 & 5,080 & 7,908 \\
\hline pooled & 0.955 & 0.928 & 0.869 \\
$\bar{R}^{2}$ & 0.968 & 0.991 & 0.991 \\
$\#$ observations & 53,503 & 142,231 & 221,430 \\
\hline \hline
\end{tabular}

The distribution of the slope estimates is illustrated in Figure 2. Note that all estimated slope coefficients are highly statistically significant and that in all years the goodness-of-fit indicator is very high, especially for estimates at the 2- and 3-digit level of data aggregation. ${ }^{8}$ We thus conclude:

\section{Empirical result 1}

The distribution of revealed comparative advantage for the years 1970 through 1997 as measured with the Balassa index at either the 2-digit, 3-digit, or 4-digit level of data aggregation follows the rank-size rule, whereby for the respective levels of data aggregation the estimated power coefficient is in $[0.88,1.03]$, $[0.90,0.98]$ and $[0.85,0.92]$.

\footnotetext{
${ }^{8}$ An obvious additional test for examing the validity of the linearity of the relationship is to include a quadratic term in (2), as in Black and Henderson (2003). However, as illustrated by Gabaix and Ioanides (2004), it is very likely that the estimated coefficient of this quadratic term will turn out to be statistically significant in situations where the underlying data are obtained from a data generating process that is known to comply perfectly to Zipf's law.
} 
Figure 2. Distribution of the estimated per-year slope coefficients at the 2-digit, 3-digit, and 4-digit level of data aggregation.

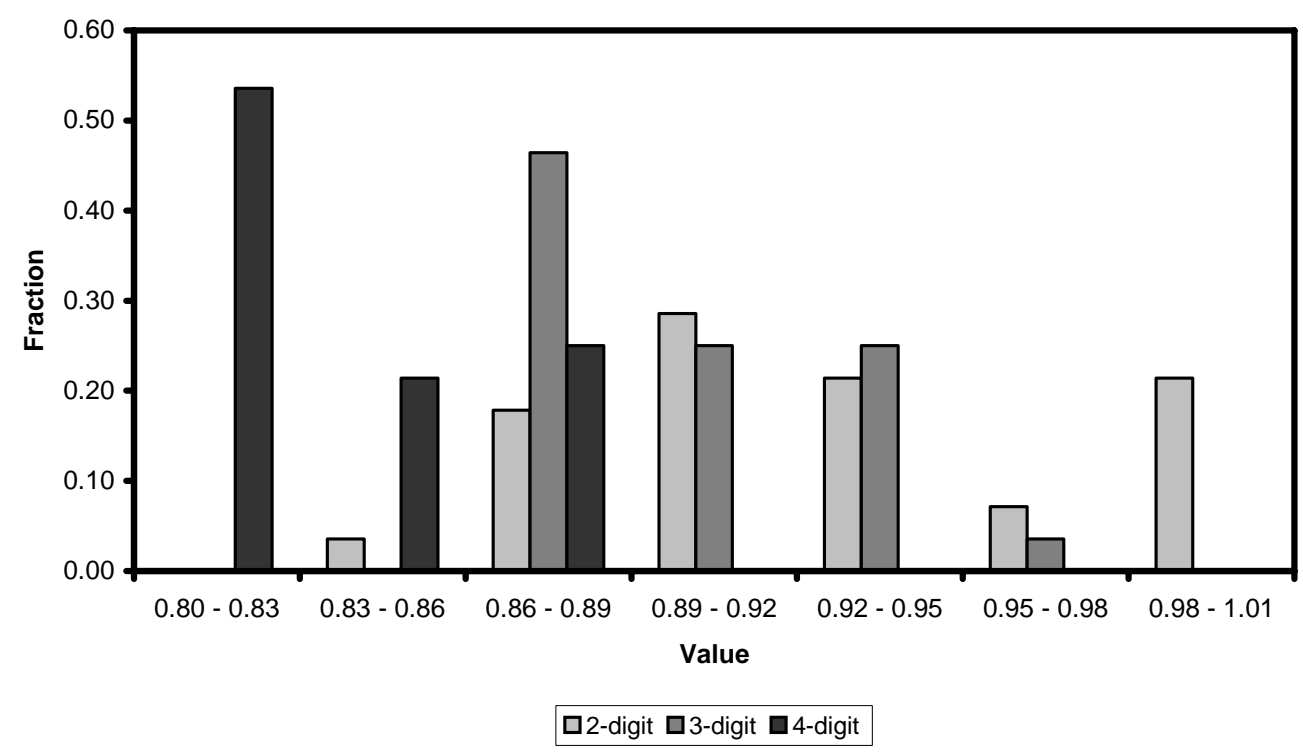

To examine whether Zipf's law applies in particular a $t$-test is conducted, which leads to:

\section{Empirical result 2}

The distribution of revealed comparative advantage for the years 1970 through 1997 as measured with the Balassa index at either the 2-digit, 3-digit, or 4-digit level of data aggregation follows Zipf's law in, respectively, $69 \%, 24 \%$ and $0 \%$ of all sample years.

\subsection{Dimension II: country}

The country dimension is captured by the following equation:

$$
\ln \left[\operatorname{rank}\left(B I_{i, t}^{j}\right)-\frac{1}{2}\right]=\beta_{0, i}+\beta_{1, i} \ln \left[B I_{i, t}^{j}\right], \quad i=1, \cdots, 166 .
$$

Table 2 provides summary statistics of the related estimates for the different levels of aggregation whereas details of the individual estimates for the 166 countries are in Table A2 in Appendix B. 
Table 2. Summary statistics of the 166 per-country Gabaix-Ibragimov estimates of the slope parameter in (4).

\begin{tabular}{lrrr}
\hline \hline & 2-digit & 3-digit & 4-digit \\
\hline average & 1.048 & 0.964 & 0.890 \\
median & 0.939 & 0.839 & 0.790 \\
variance & 0.226 & 0.188 & 0.150 \\
min & 0.498 & 0.366 & 0.444 \\
$\max$ & 3.710 & 3.326 & 2.948 \\
average \# observations & 322 & 857 & 1,334 \\
\hline \hline
\end{tabular}

All estimated slope coefficients are statistically significant, and in almost all cases the goodness-of-fit is very high (the median value of the latter is $89.5,92.7$, and 94.2 per cent at the 2-digit, 3-digit, and 4-digit level, respectively). Hence:

\section{Empirical result 3}

The distribution of revealed comparative advantage for the 166 sample countries as measured with the Balassa index at either the 2-digit, 3-digit, or 4-digit level of data aggregation follows the rank-size rule, whereby for the respective levels of data aggregation the estimated power coefficient is in $[0.50,3.71],[0.37,3.33]$ and $[0.44,2.95]$.

Figure 3. Distribution of the estimated per-country slope coefficients at the 2-digit, 3digit, and 4-digit level of data aggregation.

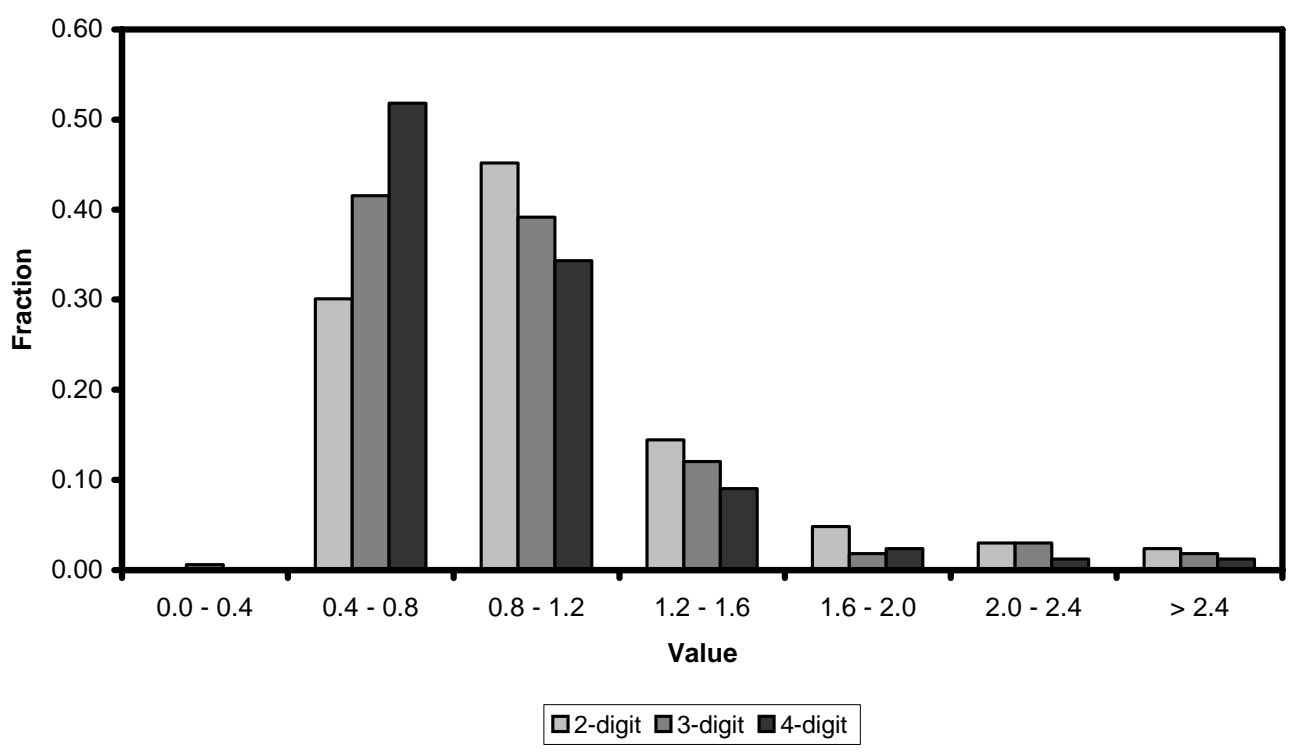


As is clear from Table 2 and illustrated in Figure 3, the estimated power exponents vary considerably between countries. At the 3-digit level, for example, the maximum estimate of 3.326 for Germany is almost ten times as high as the minimum estimate of 0.366 for Comoros. Although the goodness-of-fit also varies more than before, in all cases the explanatory power remains high. ${ }^{9}$ This suggests that an individual country exhibits its own characteristic distribution of revealed comparative advantage which might be related to country factors (an issue taken up further in Section 5 below). Finally, considering the $t$-tests for examining whether or not Zipf's law applies leads us to observe:

\section{Empirical result 4}

The distribution of revealed comparative advantage for the 166 sample countries as measured with the Balassa index at either the 2-digit, 3-digit, or 4-digit level of data aggregation follows Zipf's law in, respectively, $38 \%, 20 \%$ and $13 \%$ of all cases.

\subsection{Dimension III: sectors}

The sector dimension is examined with the following equation:

$$
\ln \left[\operatorname{rank}\left(B I_{i, t}^{j}\right)-\frac{1}{2}\right]=\gamma_{0}^{j}+\gamma_{0}^{j} \ln \left[B I_{i, t}^{j}\right], \quad j=1, \cdots, J,
$$

whereby $J$ refers to the number of sectors for the particular level of data aggregation. At the 2-digit level there are 66 different sectors, at the 3-digit level 225 sectors are distinguished, and 419 sectors are identified at the 4-digit level. Table 3 provides the summary statistics for the sector estimates and Table B3 in Appendix B contains the details of all sector estimates separately. Figure 4 illustrates the distribution of the estimated sector exponents.

Table 3. Summary statistics of the 66 2-digit, the 225 3-digit sectors, and the 419 4digit per-sector Gabaix-Ibragimov estimates of the slope parameter in (5).

\begin{tabular}{lrrr}
\hline \hline & 2-digit & 3-digit & 4-digit \\
\hline average & 1.411 & 1.347 & 1.198 \\
median & 1.225 & 1.253 & 1.101 \\
variance & 0.385 & 0.295 & 0.220 \\
min & 0.646 & 0.394 & 0.415 \\
max & 3.113 & 3.420 & 3.282 \\
average \# observations & 811 & 632 & 528 \\
\hline \hline
\end{tabular}

\footnotetext{
${ }^{9}$ This holds a fortiori if the number of observations is taken into account; on average a relatively low goodness-of-fit is related to a limited number of observations. For instance, the regression for Germany is based on 2,942 observations while the estimate for Comoros uses 142 observation only (Table B2).
} 
Figure 4. Distribution of the estimated per-sector slope coefficients at the 2-digit, 3digit, and 4-digit level of data aggregation.

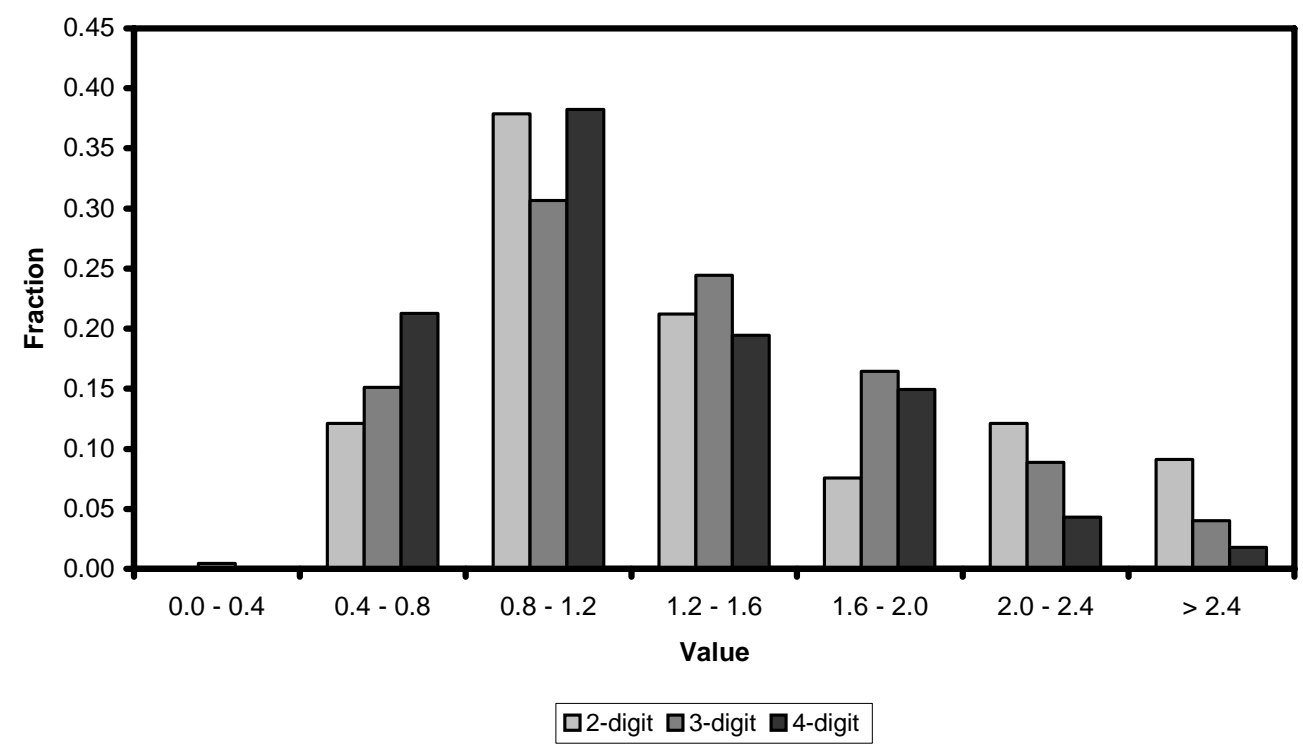

We arrive at similar conclusions as for the country dimension. The estimated power exponents vary considerably between sectors even for the same level of data aggregation. At the 3-digit level, for instance, the minimum estimate is 0.394 for sector 264 ("jute and other textile bast fibres, nes, raw/processed") and the maximum estimate is 3.420 for sector 784 ("parts and accessories of 722, 781, 782, 783 [relating to motor vehicles]"). Further, the goodness-of-fit for the individual estimates remains high: the median is $94.3,94.9$, and 94.7 per cent at the 2-digit, 3-digit, and 4-digit level, respectively. We thus conclude:

\section{Empirical result 5}

The distribution of revealed comparative advantage for the 66 2-digit sectors, the 225 3-digit sectors, and the 419 4-digit sectors as measured with the Balassa index follows the rank-size rule, whereby for the respective levels of data aggregation the estimated power coefficient is in $[0.65,3.11],[0.39,3.42]$ and $[0.42,3.28]$.

The considerable variation across sectors in the estimated power-law coefficients is also examined further in Section 5 below. For now we observe that for a substantial number of sectors Zipf's law applies: 


\section{Empirical result 6}

The distribution of revealed comparative advantage for the 66 2-digit sectors, the 225 3-digit sectors, and the 419 4-digit sectors as measured with the Balassa index follows Zipf's law in, respectively, $16 \%, 17 \%$ and $26 \%$ of all cases.

\section{Discussion}

We thus far have seen that revealed comparative advantage always complies to the rank-size rule, and that a modest share of the estimated power exponents does not differ significantly from unity. In addition, the estimated power law exponents do not differ from year to year, but they do vary between countries and between sectors.

\subsection{Characteristics of estimated country exponents}

The significant differences in estimated power law coefficients between countries suggests that these estimates are related to country characteristics. To give further weight to this conjecture we relate the estimated power law coefficients to country characteristics that can be expected to affect the value of the Balassa index, including country size (measured by GDP and number of inhabitants), export size, openness (exports as a fraction of GDP), and export breadth (measured as the number of sectors in which a comparative advantage is obtained). This leads us to consider the following equation:

$$
\begin{aligned}
\gamma_{i t}= & \beta_{i}+\beta_{1} \gamma_{i t-1}+\beta_{2} \ln \left(G D P_{i t}\right)+\beta_{3} \ln \left(P O P_{i t}\right)+\beta_{4} \ln \left(E X P_{i t}\right)+\beta_{5} \frac{E X P_{i t}}{G D P_{i t}} \\
& +\beta_{6} \ln \left(E X P S_{i t}\right)+\varepsilon_{i t},
\end{aligned}
$$

whereby $\gamma_{i t}$ is the estimated value of the power-law exponent for country $i$ in year $t, \beta_{1}$ is a country-specific fixed effect, POP is the population size (measured in 1000 persons), EXP is the value of exports (measure in 1000 US \$), EXPS is the number of export sectors, and $\varepsilon$ is assumed to be iid with zero mean and constant variance..$^{10}$ However, in (6) the estimated power-law exponent $\gamma_{i t-1}$ depends on $\beta_{i}$ which leads to biased estimates. To solve this problem first differences are considered:

$$
\begin{aligned}
\gamma_{i t}-\gamma_{i t-1}= & \beta_{1}\left(\gamma_{i t-1}-\gamma_{i t-2}\right)+\beta_{2}\left(\ln \left(G D P_{i t}\right)-\ln \left(G D P_{i t-1}\right)\right) \\
& +\beta_{3}\left(\ln \left(P O P_{i t}\right)-\ln \left(P O P_{i t-1}\right)\right)+\beta_{4}\left(\ln \left(E X P_{i t}\right)-\ln \left(E X P_{i t-1}\right)\right) \\
& +\beta_{5}\left(\frac{E X P_{i t}}{G D P_{i t}}-\frac{E X P_{i t-1}}{G D P_{i t-1}}\right)+\beta_{6}\left(\ln \left(E X P S_{i t}\right)-\ln \left(E X P S_{i t-1}\right)\right)+\varepsilon_{i t}-\varepsilon_{i t-1} .
\end{aligned}
$$

This creates yet another problem as $\gamma_{i t-1}$ is correlated with $\varepsilon_{i t-1}$. Following Verbeek (2000) this is restored by using $\gamma_{i t-2}$ as an instrument for $\left(\gamma_{i t-1}-\gamma_{i t-2}\right)$.

\footnotetext{
${ }^{10}$ See Appendix A for the several data sources.
} 
The results of the panel estimates are in Table 4, where the estimated power-law coefficients are from the regressions of Section 4.2. ${ }^{11}$ Considering these results prompts two observations. First, although the specification in (7) is not obtained from a formally derived first-order condition, the strong significance of most estimated coefficients does suggest that the cross-country variation of the estimated power law coefficient is related to countryspecific characteristics. Second, at the 3-digit and 4-digit level the estimated panel coefficients are quite comparable. At the 2-digit level the export breath variable is still significant but with an opposite sign. This is due to the related drop in the number of distinguished sectors which alienates the export breadth variable in the 2-digit case from those in which either 3-digit or 4-digit export flows are considered. We conclude:

\section{Empirical result 7}

The estimated power coefficient of the rank-size rule for revealed comparative advantage as measured with the Balassa index differs significantly across countries. These differences are related to the following country-specific characteristics: country size, export size, export breadth, and openness.

Table 4. Panel estimates for explaining cross country differences in estimated power law coefficients (6); dependent variable: first differences estimated power law coefficients.

\begin{tabular}{lrrr}
\hline \hline & 2-digit & 3-digit & 4-digit \\
\hline lagged power-law coefficient & 0.03 & -0.01 & -0.01 \\
country size (GDP) & $(1.96)$ & $(2.28)$ & $(2.27)$ \\
& 0.66 & 0.31 & 0.22 \\
country size (POP) & $(2.60)$ & $(4.56)$ & $(3.69)$ \\
& 0.04 & -0.00 & 0.32 \\
export size & $(0.06)$ & $(0.00)$ & $(1.63)$ \\
& -0.54 & -0.04 & -0.08 \\
export breadth & $(11.12)$ & $(3.44)$ & $(8.06)$ \\
& -0.56 & 0.08 & 0.05 \\
openness & $(8.22)$ & $(4.48)$ & $(3.27)$ \\
& 345.26 & 67.52 & 82.83 \\
\# observations & $(3.57)$ & $(2.64)$ & $(3.12)$ \\
\hline \hline
\end{tabular}

${ }^{*} t$-values are within brackets.

${ }^{11}$ In total the panel study is based on 13,944 (not reported) annually estimated power exponents at the country level (namely 28 years $\times 166$ countries $\times 3$ levels of aggregation). 


\subsection{Characteristics of estimated sector exponents}

Differences across sectors regarding the estimated power law coefficient can be structured effectively according to the core analysis of international trade: factor intensity. To that end we use the factor intensity classification of the International Trade Center, the joint UNCTAD/WTO organization. In particular we have the following five broad factor intensity categories (within brackets the number of 3-digit sectors belonging to the particular category; note that there are 5 sectors that are not classified; see Hinloopen and van Marrewijk, 2006): ${ }^{12}$

A. Primary products (83); including meat, dairy, cereals, fruit, coffee, sand, minerals, oil, natural gas, iron ore, and copper ore.

B. Natural-resource intensive products (21); including leather, cork, wood, lime, precious stones, pig iron, copper, aluminum, and lead.

C. Unskilled-labor intensive products (26); including various textiles and garments, clothing, glass, pottery, ships, furniture, footwear, and office supplies.

D. Human-capital intensive products (43); including synthetic colors, pigments, perfumes, cosmetics, rubber and tires, tubes, pipes, various types of steel and iron, cutlery, televisions, radios, cars, watches, and jewellery.

E. Technology intensive products (62); including various chemicals, medicaments, plastics, engines, generators, machines, tools, pumps, telecommunications and photo equipment, optical equipment, and aircraft.

Table 5 contains the average estimated power-law coefficients for these factor intensity categories. It appears that the estimated power exponents are about equal for primary products and natural-resource intensive products. Similarly, they are about equal for technologyintensive products and human-capital intensive products. Moreover, the estimated exponents tend to be lower for primary products than for unskilled-labor intensive products, which in turn tend to be lower than that for human-capital intensive products. Indeed, according to a two-sided $t$-test of mean differences the following ordering applies:

$$
\gamma_{\text {primary }}=\gamma_{\text {natural-resource }}<\gamma_{\text {unskilled-labor }}<\gamma_{\text {human-capital }}=\gamma_{\text {technology }}
$$

${ }^{12}$ We first made some adjustments to get from the SITC Rev. 3 codes to the codes in Feenstra et al. (1997); see http://people.few.eur.nl/vanmarrewijk/eta for further details. 
Table 5. Pair wise $t$-tests for equality of the mean of estimated power-law coefficients across sectors (3-digit).

\begin{tabular}{ccccccc}
\hline \hline & $\mathrm{A}$ & $\mathrm{B}$ & $\mathrm{C}$ & $\mathrm{D}$ & Mean estimate & $t$-value for $\mathrm{H}_{0}: \bar{\gamma}=1$ \\
\hline $\mathrm{A}$ & $*$ & & & & 0.94 & 2.05 \\
$\mathrm{~B}$ & 0.86 & $*$ & & & 1.01 & 0.12 \\
$\mathrm{C}$ & 5.16 & 3.25 & $*$ & & 1.37 & 4.73 \\
$\mathrm{D}$ & 8.59 & 5.93 & 2.73 & $*$ & 1.67 & 13.71 \\
$\mathrm{E}$ & 13.10 & 8.15 & 4.51 & 1.37 & 1.81 & 8.42 \\
\hline \hline
\end{tabular}

In addition, we have tested whether Zipf's law applies for the five different factor intensity categories. Although the mean value of the estimated power-law coefficient for naturalresource intensive products does not differ from that for primary products, it is only for the former product category that Zipf's law applies in particular (see Table 5). We thus conclude:

\section{Empirical result 8}

The estimated power coefficient of the rank-size rule for revealed comparative advantage as measured with the Balassa index differs significantly across sectors ordered according to factor intensities. For all sectors the rank-size rule applies; for natural-resource intensive sectors Zipf's law holds in particular.

\section{Conclusions}

The analysis of the evolution of a country's apparent strong export sectors as indicated by a revealed comparative advantage using the Balassa index (or its monotonic transformations) is complicated by the lack of a characterization of the distribution of this index. Using a comprehensive international trade data set we reveal an empirical regularity of revealed comparative advantage that alleviates some of this complication: its obedience to the ranksize rule along the time, country, and sector dimension. Our results are obtained using the estimator recently developed by Gabaix and Ibragimov (2006) which yields unbiased estimates absent data contamination. As our analysis is based in total on 1,295 estimated power exponents we are quite confident that our findings are representative for the phenomenon documented here.

This empirical finding calls for theoretical explorations, possibly along the lines of the recent explanations for city size distributions (Gabaix (1999), Brakman et al. (2001), and Eeckhout, 2004). The variation in estimated power law coefficients across countries and sectors suggests that these theories should take into account country and/or sector characteristics. This is confirmed by the panel estimates that document the empirical relation 
between estimated power law coefficients and country specific characteristics, including country size, openness, and export breadth. The market size variables point to theories of imperfect competition in which the home-market effect, the competition for large markets, and location effects through intra-industry trade linkages play a prominent role. ${ }^{13}$

At the sectoral level the estimated power law coefficients differ systematically across sectors classified along factor intensity. This finding points to Heckscher-Ohlin-Samuelson type international trade theories which are rooted in factor abundance. To the extent that countries differ in technology, physical- and human capital abundance, or (un)skilled labor abundance, each of which affects the sectoral composition of revealed comparative advantage, this should also be taken into consideration when analyzing the estimated power exponent at the country level. We leave that and the theoretical explorations for future research.

\section{References}

Axtell, R.L. (2001), “Zipf distribution of U.S. firm sizes”, Science 293: 1818 - 1820.

Balassa, B. (1965), "Trade liberalization and 'revealed' comparative advantage", The Manchester School of Economic and Social Studies 33: 92 - 123.

Beirlant, J., G. Dierckx, Y. Goegebeur, and G. Matthys (1999), “Tail index estimation and an exponential regression model", Extremes 2: 177 - 200.

Beirlant, J., Y. Goegebeur, J. Teugels, and J. Segers (2004), Statistics of extremes, Wiley Series in Probability and Statistics, John Wiley \& Sons Ltd., Chichester.

Black, D. and V. Henderson, 2003, "Urban evolution in the USA", Journal of Economic Geography, 3: 343 - 372.

Brakman, S., H. Garretsen, and C. van Marrewijk (2001), An introduction to geographical economics: trade, location, and growth, Cambridge University Press, Cambridge, U.K.

Eeckhout, J. (2004), “Gibrat's law for all cities,” American Economic Review 94: 1429-1451.

Embrechts, P., C. Kluppelberg, and T. Mikosch (1997), Modelling extremal events for insurance and finance, Springer, New York.

Evenett, S.J., and W. Keller (2002), "On theories explaining the success of the gravity equation", Journal of Political Economy 110: 281-316.

Feenstra, R., R. Lipsey, and H. Bowen (1997), "World trade flows, 1970 - 1992, with production and tariff data", NBER Working Paper No. 5910.

Feenstra, R. C. (2000), World trade flows; 1980 - 1997, Institute of Governmental Affairs, University of California, Davis.

\footnotetext{
${ }^{13}$ See also the related recent theories explaining the empirical success of the gravity equation in Evenett and Keller (2002) and the geographical economics theories on the endogenous determination of location in Fujita, Krugman, and Venables (1999).
} 
Fertö, I., and L.J. Hubbard (2003), "Revealed comparative advantage and competitiveness in Hungarian Agri-food sectors", World Economy, 26: 247 - 259.

Feuerverger, A., and P. Hall (1999), "Estimating a tail exponent by modelling departure from a Pareto distribution", Annals of Statistics 27: 760-781.

Frankel, J. (ed.), 1998, The regionalization of the world economy, NBER.

Fujita, M., P.R. Krugman, and A.J. Venables (1999), The spatial economy: cities, regions, and international trade, MIT Press, Cambridge, MA.

Gabaix, X. (1999), “Zipf’s Law for cities”, Quarterly Journal of Economics 114: 739 - 767.

Gabaix, X., P. Gopikrishnan, V. Plerou, and H.E. Stanley (2003), "A theory of power-law distributions in financial market fluctuations", Nature 423: $267-270$.

Gabaix, X., and Y. Ioannides (2004), "The evolution of city size distributions", in: J.V. Henderson and J.-F. Thisse (eds.), Handbook of Regional and Urban Economics IV: Cities and Geography, North-Holland: $2341-2378$.

Gabaix, X., and R. Ibragimov (2006), "Rank-1/2: a simple way to improve the OLS estimation of tail exponents", MIT, NBER, and Harvard University, mimeo.

Hall, P. (1982), On some simple estimates of an exponent of regular variation", Journal of the Royal Statistical Society, Series B 44: 37-42.

Hill, B.M. (1975), "A simple approach to inference about the tail of a distribution", Annals of Statistics 3: $1163-1174$.

Hillman, A.L. (1980), "Observations on the relation between 'revealed comparative advantage' and comparative advantage as indicated by pre-trade relative prices", Weltwirtschaftliches Archiv 116: 315 - 321.

Hinloopen, J., and C. van Marrewijk (2001), "On the empirical distribution of the Balassa index", Weltwirtschaftliches Archiv 137: 1 - 35.

Hinloopen, J., and C. van Marrewijk (2006), "The empirical relevance of the Hillman condition for revealed comparative advantage", Applied Economics, forthcoming.

Ibragimov, R., and P.C.B. Phillips (2004), "Regression asymptotics using martingale convergence methods", Cowles Foundation, Discussion Paper No. 1473.

Janssen, D., and C.G. de Vries (1991), "On the frequency of large stock returns: putting booms and busts into perspective", Review of Economics and Statistics 73: 18 - 32 .

Krugman, P.R. (1996), "Confronting the mystery of urban hierarchy", Journal of the Japanese and International Economies 10: 399 - 418.

Liesner, H.H. (1958), "The European Common Market and British industry", Economic Journal 68: $302-316$.

Maddison, A. (2003), The world economy: historical statistics, OECD, Paris, France.

Mandelbrot, B. (1963), "The variation of certain speculative prices", Journal of Business 36: $394-419$. 
Nitsch, V. (2005), “Zipf zipped”, Journal of Urban Economics 57: 86 - 100.

Okuyama, K., M. Takayasu, and H. Takayasu (1999), "Zipf's Law in income distribution of companies", Physica A 269: 125 - 131.

Soo, K.T. (2005), "Zipf's law for cities: a cross-country investigation”, Regional Science and Urban Economics 35: 239 - 263.

Phillips, P.C.B. (2007), "Regression with slowly varying regressors", Econometric Theory, forthcoming.

Porter, M. (1990), The competitive advantage of nations, MacMillan, London.

Rose, A.K. (2005), "Cities and countries", NBER Working Paper No. 11762.

Rosen, K.T., and M. Resnick (1980), "The size distribution of cities", Journal of Urban Economics 8: 165 - 186 .

Semmler, W. (ed.), 1994, Business cycles: theory and empirical evidence, Kluwer Academic Publishers.

Svaleryd, H. and J. Vlachos (2005), "Financial markets, the pattern of industrial specialization and comparative advantage: evidence from OECD countries", European Economic Review, 49: 113 - 144.

Verbeek, M., 2000, A guide to modern econometrics, John Wiley and Sons.

World Bank (2005), World Development Indicators, Washington D.C., U.S.A.

Zipf, G.K. (1949), Human behavior and the principle of least effort, Addison-Wesley, Cambridge, MA. 


\section{Appendix A Data}

Two separate data sets compiled by the Center for International Data, University of California, Davis (CID/UCD), were merged, the first covering the years 1970 through 1993 (see Feenstra, Lipsey and Bowen, 1997) and the second covering the years 1980 through 1997 (see Feenstra, 2000). For the overlapping years, the data from the latter source are used. The data set contains bilateral trade flows between 183 trading partners, including n.e.s. (not elsewhere specified) regions for trade flows that could not be classified further than within a broad geographical region (such as "Middle East", or "North Africa"), an "Areas n.e.s." region for trade flows that cannot be attributed to any country or to any of the used broad geographical regions but that do come from a well-defined geographical region, and an "Unknown Partner" category for trade flows that could not be attributed at all due to various reasons (see Feenstra, 2000). This leaves a sample of 165 genuine countries

The bilateral trade flows are decomposed into 1,249 sectors, comprising 747 genuine 4-digit sectors, based on SITC (Standard International Trade Classification), revision 2. The remaining 502 sectors refer to aggregates at the 1-, 2-, or 3-digit level, and a "Non-identified products" category. The 4-digit subset contains $60.39 \%$ of all trade, the 3 -digit subset covers $99.46 \%$ of all trade, and the 2-digit subset comprises $99.67 \%$ of all trade.

The data were first compiled by Statistics Canada and made available through the CID/UCD (see Feenstra, 2000). The former makes use of various sources (according to Statistics Canada $87 \%$ of all trade flows is based on independent sources of both imports and exports, while $98 \%$ is based on reports of at least one side of trade), yielding a rather complete coverage of world trade flows. The CID/UCD transforms the data such that trade flows for all years, all countries, and all industry groups are consistent and presented in a unified manner. Each observation in the raw data consists of four entries: importing country, exporting country, sector, and size of the trade flow (in 1,000 US \$). The data are thus classified according to the importing country. This is not to say that the data are based on import sources only, as explained above. After merging the two separate datasets a second dataset is created by "inverting" the data, in that all trade is classified according to the exporting country.

The income and population data are taken from the World Bank Development Indicators 2005 except for Taiwan. Those data are based on own calculations using the Maddison (2003) data set and complementary material taken from the website of the National Statistics Office of Taiwan (http://eng.stat.gov.tw/mp.asp?mp=5). 
Table A1 Sample countries

\begin{tabular}{|c|c|c|c|}
\hline \multicolumn{2}{|c|}{ Country } & \multicolumn{2}{|c|}{ Country } \\
\hline 1 & South Africa & 91 & Belize \\
\hline 2 & Algeria & 92 & Falkland Isl \\
\hline 3 & Liby Arab Jm & 93 & French Guiana \\
\hline 4 & Morocco & 94 & Guyana \\
\hline 5 & Western Sahara & 95 & Panama \\
\hline 6 & Sudan & 96 & Surinam \\
\hline 7 & Tunisia & 98 & Israel \\
\hline 8 & Egypt & 99 & Japan \\
\hline 10 & Cameroon & 100 & Bahrain \\
\hline 11 & Central Afr. Rep. & 101 & Cyprus \\
\hline 12 & Chad & 102 & Iran \\
\hline 13 & Congo & 103 & Iraq \\
\hline 14 & Gabon & 104 & Jordan \\
\hline 16 & Angola & 105 & Kuwait \\
\hline 17 & Br.Ind.Oc.Tr & 106 & Lebanon \\
\hline 18 & Burundi & 107 & Oman \\
\hline 19 & Comoros & 108 & Qatar \\
\hline 20 & Zaire & 109 & Saudi Arabia \\
\hline 21 & Benin & 110 & Fm Dem Yemen \\
\hline 22 & Eq. Guinea & 111 & Syrn Arab Rp \\
\hline 23 & Ethiopia & 112 & Untd Arab Em \\
\hline 25 & Djibouti & 113 & Turkey \\
\hline 26 & Gambia & 114 & Fm Yemen \\
\hline 27 & Ghana & 115 & Yemen \\
\hline 28 & Guinea & 117 & Afghanistan \\
\hline 29 & Cote D'ivoire & 118 & Bangladesh \\
\hline 30 & Kenya & 119 & Bhutan \\
\hline 31 & Liberia & 120 & Brunei \\
\hline 32 & Madagascar & 121 & Myanmar (Burma) \\
\hline 33 & Malawi & 122 & Cambodia \\
\hline 34 & Mali & 123 & Sri Lanka \\
\hline 35 & Mauritania & 124 & Hong Kong \\
\hline 36 & Mauritius & 125 & India \\
\hline 37 & Mozambique & 126 & Indonesia (Incl Macau) \\
\hline 38 & Niger & 127 & Korea Rp (South) \\
\hline 39 & Nigeria & 128 & Laos P.Dem.R \\
\hline 40 & Guinea-Bissau (Incl Cape Verde) & 129 & Malaysia \\
\hline 41 & Reunion & 130 & Maldives \\
\hline 42 & Rwanda & 131 & Nepal \\
\hline 43 & St.Helena & 132 & Pakistan \\
\hline 44 & Senegal & 133 & Philippines \\
\hline 45 & Seychelles & 134 & Singapore \\
\hline 46 & Sierra Leone & 135 & Thailand \\
\hline 47 & Somalia & 136 & Taiwan \\
\hline 48 & Zimbabwe & 137 & China \\
\hline 49 & Togo & 138 & Korea D P Rp (North) \\
\hline 50 & Uganda & 139 & Mongolia \\
\hline 51 & Untd Rp Tanzania & 140 & Vietnam \\
\hline 52 & Burkina Faso & 142 & Belgium-Lux. \\
\hline 53 & Zambia & 143 & Denmark (Incl Faroe Islds) \\
\hline
\end{tabular}


Table A1 Sample countries (continued)

\begin{tabular}{ll|ll}
\hline \hline Nr. & Name & Nr. & Name \\
\hline 55 & Canada & 144 & France \\
56 & Usa & 145 & Germany \\
57 & Bermuda & 146 & Greece \\
58 & Greenland & 147 & Ireland \\
59 & St Pierre Miqu & 148 & Italy \\
60 & Argentina & 149 & Netherlands \\
61 & Bolivia & 150 & Portugal \\
62 & Brazil & 151 & Spain \\
63 & Chile & 152 & United Kingdom \\
64 & Colombia & 154 & Austria \\
65 & Ecuador & 155 & Finland \\
66 & Mexico & 156 & Iceland \\
67 & Paraguay & 157 & Norway \\
68 & Peru & 158 & Sweden \\
69 & Uruguay & 159 & Switzerland \\
70 & Venezuela & 161 & Gibraltar \\
72 & Costa Rica & 162 & Malta \\
73 & El Salvador & 164 & Albania \\
74 & Guatemala & 165 & Bulgaria \\
75 & Honduras & 166 & Czechoslovakia \\
76 & Nicaragua & 167 & Fm German Dm Rp (East) \\
78 & Bahamas & 168 & Hungary \\
79 & Barbados & 169 & Poland \\
80 & Cayman Islds & 170 & Romania \\
81 & Cuba & 172 & Fm Yugoslavia \\
82 & Dominican Rp & 173 & Fm Ussr \\
83 & Guadeloupe (Incl Martinique) & 174 & Australia \\
84 & Haiti & 175 & New Zealand \\
85 & Jamaica & 176 & Solomon Islds \\
86 & Neth Antilles & 177 & Fiji \\
87 & St Kitts Nev (Incl Dominica, & 178 & Kiribati (Incl Solomon Islds, Tonga, \\
& Montserrat, St Luca,St Vinct, & & Tuvalu) \\
& Grenada) & 179 & New Caledonia (Incl Fr Polynesia, \\
88 & Trinidad-Tobago & & Vanuata) \\
& & 180 & Papua N.Guinea \\
89 & Turks Caicos Isl & & \\
\hline \hline & & $n$ & \\
\hline
\end{tabular}

Other geographical regions in data set (nes = not elsewhere specified)

\begin{tabular}{ll|ll} 
Nr. & Name & Nr. & Name \\
\hline 9 & North Africa nes & 141 & Asia Cpe nes \\
15 & Ceuca nes & 153 & Eec nes \\
24 & Fr.So.Ant.Tr & 160 & Efta nes \\
54 & Other Africa nes & 163 & Other Eur nes \\
71 & Laia nes & 171 & Fm Eur Cpe nes \\
77 & Cacm nes & 181 & Oth. Oceania nes \\
90 & Caribbean nes & 182 & Areas nes \\
97 & Rest America nes & 183 & Unknown Partner \\
116 & Middle East nes & &
\end{tabular}

\section{Appendix B Estimates}


Table B1 GI power exponent estimates of Rank-Size rule; BI > 1 , time dimension ( $\alpha_{t}$ estimates)

\begin{tabular}{|c|c|c|c|c|c|c|c|c|c|c|c|c|}
\hline \multirow[b]{2}{*}{ year } & \multicolumn{4}{|c|}{ 2-digit trade flows } & \multicolumn{4}{|c|}{ 3-digit trade flows } & \multicolumn{4}{|c|}{ 4-digit trade flows } \\
\hline & estimate & st error & fit & \# obs & estimate & st error & fit & \# obs & estimate & st error & fit & \# obs \\
\hline 1970 & 1.022 & 0.036 & 0.961 & 1,646 & 0.968 & 0.021 & 0.983 & 4,261 & 0.907 & 0.015 & 0.982 & 7,081 \\
\hline 1971 & 1.016 & 0.036 & 0.961 & 1,636 & 0.960 & 0.021 & 0.986 & 4,304 & 0.894 & 0.015 & 0.983 & 7,231 \\
\hline 1972 & 1.012 & 0.035 & 0.957 & 1,703 & 0.961 & 0.020 & 0.988 & 4,479 & 0.898 & 0.015 & 0.984 & 7,351 \\
\hline 1973 & 1.031 & 0.035 & 0.960 & 1,719 & 0.978 & 0.021 & 0.990 & 4,533 & 0.915 & 0.015 & 0.987 & 7,591 \\
\hline 1974 & 1.023 & 0.034 & 0.964 & 1,789 & 0.981 & 0.020 & 0.991 & 4,838 & 0.904 & 0.014 & 0.989 & 8,134 \\
\hline 1975 & 1.008 & 0.034 & 0.966 & 1,793 & 0.964 & 0.020 & 0.992 & 4,779 & 0.899 & 0.014 & 0.990 & 8,017 \\
\hline 1976 & 0.999 & 0.033 & 0.963 & 1,802 & 0.958 & 0.019 & 0.992 & 4,826 & 0.883 & 0.014 & 0.990 & 7,889 \\
\hline 1977 & 1.017 & 0.034 & 0.960 & 1,794 & 0.973 & 0.020 & 0.991 & 4,850 & 0.891 & 0.014 & 0.990 & 7,947 \\
\hline 1978 & 0.979 & 0.031 & 0.966 & 1,961 & 0.926 & 0.018 & 0.991 & 5,147 & 0.852 & 0.013 & 0.989 & 8,338 \\
\hline 1979 & 0.977 & 0.032 & 0.970 & 1,906 & 0.931 & 0.018 & 0.993 & 5,073 & 0.854 & 0.013 & 0.991 & 8,272 \\
\hline 1980 & 0.962 & 0.030 & 0.970 & 2,015 & 0.928 & 0.018 & 0.994 & 5,379 & 0.855 & 0.013 & 0.992 & 8,212 \\
\hline 1981 & 0.953 & 0.030 & 0.968 & 2,017 & 0.924 & 0.018 & 0.992 & 5,405 & 0.850 & 0.013 & 0.988 & 8,129 \\
\hline 1982 & 0.943 & 0.030 & 0.975 & 2,021 & 0.920 & 0.018 & 0.992 & 5,266 & 0.857 & 0.014 & 0.989 & 7,985 \\
\hline 1983 & 0.946 & 0.030 & 0.966 & 1,935 & & 0.018 & 0.992 & 5,067 & 0.861 & 0.014 & 0.987 & 7,648 \\
\hline 1984 & 0.938 & 0.030 & 0.972 & 1,917 & 0.915 & 0.018 & 0.992 & 5,106 & 0.858 & 0.014 & 0.989 & 7,681 \\
\hline 1985 & 0.951 & 0.031 & 0.964 & 1,937 & 0.922 & 0.018 & 0.989 & 5,045 & 0.859 & 0.014 & 0.989 & 7,653 \\
\hline 1986 & 0.945 & 0.031 & 0.966 & 1,869 & 0.912 & 0.018 & 0.989 & 5,008 & 0.856 & 0.014 & 0.990 & 7,527 \\
\hline 1987 & 0.940 & 0.031 & 0.964 & 1,891 & 0.909 & 0.018 & 0.990 & 5,057 & 0.860 & 0.014 & 0.990 & 7,575 \\
\hline 1988 & 0.947 & 0.030 & 0.966 & 1,928 & 0.915 & 0.018 & 0.990 & 5,054 & 0.850 & 0.014 & 0.992 & 7,547 \\
\hline 1989 & 0.954 & 0.030 & 0.967 & 1,957 & 0.922 & 0.018 & 0.990 & 5,235 & 0.849 & 0.014 & 0.993 & 7,852 \\
\hline 1990 & 0.927 & 0.029 & 0.969 & 1,981 & 0.908 & 0.018 & 0.992 & 5,347 & 0.850 & 0.013 & 0.992 & 7,946 \\
\hline 1991 & 0.910 & 0.029 & 0.965 & 1,973 & 0.907 & 0.018 & 0.990 & 5,307 & 0.861 & 0.014 & 0.993 & 8,007 \\
\hline 1992 & 0.905 & 0.028 & 0.966 & 2,026 & 0.909 & 0.017 & 0.991 & 5,455 & 0.859 & 0.013 & 0.994 & 8,274 \\
\hline 1993 & 0.895 & 0.028 & 0.975 & 2,090 & 0.900 & 0.017 & 0.992 & 5,540 & 0.851 & 0.013 & 0.995 & 8,353 \\
\hline 1994 & 0.882 & 0.028 & 0.971 & 2,053 & 0.896 & 0.017 & 0.991 & 5,409 & 0.857 & 0.013 & 0.993 & 8,230 \\
\hline 1995 & 0.897 & 0.028 & 0.966 & 2,042 & 0.902 & 0.017 & 0.992 & 5,479 & 0.869 & 0.013 & 0.994 & 8,344 \\
\hline 1996 & 0.911 & 0.028 & 0.970 & 2,045 & 0.912 & 0.017 & 0.993 & 5,560 & 0.871 & 0.013 & 0.993 & 8,419 \\
\hline 1997 & 0.947 & 0.030 & 0.966 & 2,057 & 0.925 & 0.018 & 0.991 & 5,422 & 0.883 & 0.014 & 0.993 & 8,197 \\
\hline all & 0.955 & 0.006 & 0.968 & 53,503 & 0.928 & 0.003 & 0.991 & 142,231 & 0.869 & 0.003 & 0.991 & 221,430 \\
\hline
\end{tabular}


Table B2 GI power exponent estimates of Rank-Size rule; $B I>1$, country dimension ( $\beta_{i}$ estimates)

\begin{tabular}{|c|c|c|c|c|c|c|c|c|c|c|c|c|}
\hline \multirow[b]{2}{*}{ country } & \multicolumn{4}{|c|}{ 2-digit trade flows } & \multicolumn{4}{|c|}{ 3-digit trade flows } & \multicolumn{4}{|c|}{ 4-digit trade flows } \\
\hline & estimate & st error & fit & \# obs & estimate & st error & fit & \# obs & estimate & st error & fit & \# obs \\
\hline 1 & 1.220 & 0.079 & 0.955 & 477 & 1.100 & 0.045 & 0.926 & 1,217 & 0.968 & 0.029 & 0.915 & 2,250 \\
\hline 2 & 0.876 & 0.138 & 0.812 & 81 & 0.940 & 0.091 & 0.873 & 213 & 1.007 & 0.084 & 0.935 & 289 \\
\hline 3 & 0.958 & 0.174 & 0.884 & 61 & 1.081 & 0.140 & 0.910 & 119 & 1.109 & 0.134 & 0.916 & 138 \\
\hline 4 & 0.904 & 0.062 & 0.937 & 426 & 0.839 & 0.035 & 0.966 & 1,151 & 0.860 & 0.026 & 0.961 & 2,106 \\
\hline 5 & 0.567 & 0.087 & 0.869 & 85 & 0.537 & 0.065 & 0.908 & 137 & 0.461 & 0.057 & 0.870 & 132 \\
\hline 6 & 0.744 & 0.067 & 0.744 & 246 & 0.681 & 0.046 & 0.870 & 436 & 0.509 & 0.028 & 0.918 & 656 \\
\hline 7 & 0.980 & 0.075 & 0.889 & 338 & 0.958 & 0.043 & 0.910 & 997 & 0.884 & 0.031 & 0.955 & 1,628 \\
\hline 8 & 1.249 & 0.099 & 0.955 & 320 & 1.051 & 0.050 & 0.948 & 877 & 0.928 & 0.035 & 0.936 & 1,421 \\
\hline 10 & 0.943 & 0.075 & 0.926 & 314 & 0.820 & 0.048 & 0.917 & 582 & 0.751 & 0.038 & 0.920 & 774 \\
\hline 11 & 0.849 & 0.086 & 0.841 & 193 & 0.654 & 0.055 & 0.896 & 286 & 0.596 & 0.045 & 0.887 & 344 \\
\hline 12 & 0.583 & 0.080 & 0.836 & 107 & 0.574 & 0.063 & 0.926 & 164 & 0.552 & 0.057 & 0.959 & 189 \\
\hline 13 & 1.138 & 0.154 & 0.907 & 109 & 0.852 & 0.093 & 0.879 & 166 & 0.689 & 0.069 & 0.920 & 202 \\
\hline 14 & 1.010 & 0.125 & 0.714 & 130 & 0.722 & 0.078 & 0.870 & 171 & 0.544 & 0.054 & 0.825 & 202 \\
\hline 16 & 1.043 & 0.122 & 0.861 & 146 & 0.868 & 0.079 & 0.950 & 243 & 0.895 & 0.070 & 0.963 & 330 \\
\hline 17 & 0.713 & 0.082 & 0.953 & 151 & 0.645 & 0.060 & 0.906 & 232 & 0.579 & 0.059 & 0.919 & 192 \\
\hline 18 & 0.625 & 0.074 & 0.823 & 142 & 0.598 & 0.056 & 0.879 & 224 & 0.589 & 0.047 & 0.901 & 316 \\
\hline 19 & 0.498 & 0.079 & 0.650 & 80 & 0.366 & 0.043 & 0.839 & 142 & 0.530 & 0.057 & 0.886 & 171 \\
\hline 20 & 1.020 & 0.084 & 0.879 & 294 & 0.738 & 0.048 & 0.876 & 483 & 0.702 & 0.039 & 0.881 & 649 \\
\hline 21 & 0.690 & 0.063 & 0.847 & 237 & 0.686 & 0.044 & 0.940 & 486 & 0.588 & 0.034 & 0.978 & 593 \\
\hline 22 & 0.628 & 0.077 & 0.732 & 134 & 0.567 & 0.053 & 0.861 & 233 & 0.537 & 0.047 & 0.901 & 261 \\
\hline 23 & 0.717 & 0.061 & 0.860 & 280 & 0.725 & 0.045 & 0.932 & 510 & 0.574 & 0.030 & 0.889 & 748 \\
\hline 25 & 0.794 & 0.082 & 0.972 & 188 & 0.838 & 0.053 & 0.975 & 501 & 0.695 & 0.040 & 0.958 & 610 \\
\hline 26 & 0.617 & 0.064 & 0.768 & 188 & 0.581 & 0.045 & 0.888 & 338 & 0.530 & 0.037 & 0.889 & 411 \\
\hline 27 & 0.825 & 0.071 & 0.905 & 267 & 0.720 & 0.051 & 0.922 & 402 & 0.703 & 0.045 & 0.852 & 498 \\
\hline 28 & 0.637 & 0.073 & 0.845 & 154 & 0.612 & 0.055 & 0.896 & 247 & 0.531 & 0.045 & 0.937 & 274 \\
\hline 29 & 0.832 & 0.069 & 0.915 & 294 & 0.778 & 0.047 & 0.912 & 560 & 0.729 & 0.035 & 0.868 & 868 \\
\hline 30 & 0.910 & 0.064 & 0.950 & 400 & 0.758 & 0.036 & 0.972 & 890 & 0.821 & 0.029 & 0.953 & 1,626 \\
\hline 31 & 0.738 & 0.077 & 0.755 & 185 & 0.560 & 0.049 & 0.815 & 259 & 0.502 & 0.045 & 0.797 & 251 \\
\hline
\end{tabular}




\begin{tabular}{|c|c|c|c|c|c|c|c|c|c|c|c|c|}
\hline \multirow{2}{*}{$\begin{array}{l}\text { Table B2 } \\
\text { country }\end{array}$} & \multicolumn{4}{|c|}{ 2-digit trade flows } & \multicolumn{4}{|c|}{ 3-digit trade flows } & \multicolumn{4}{|c|}{ 4-digit trade flows } \\
\hline & estimate & st error & fit & \# obs & estimate & st error & fit & \# obs & estimate & st error & fit & \# obs \\
\hline 32 & 0.895 & 0.065 & 0.943 & 383 & 0.680 & 0.036 & 0.966 & 725 & 0.765 & 0.033 & 0.914 & 1,081 \\
\hline 33 & 0.606 & 0.058 & 0.850 & 221 & 0.595 & 0.039 & 0.935 & 462 & 0.542 & 0.028 & 0.924 & 755 \\
\hline 34 & 0.759 & 0.060 & 0.931 & 316 & 0.691 & 0.043 & 0.963 & 517 & 0.718 & 0.038 & 0.917 & 711 \\
\hline 35 & 0.577 & 0.078 & 0.631 & 111 & 0.548 & 0.053 & 0.853 & 216 & 0.597 & 0.047 & 0.905 & 316 \\
\hline 36 & 0.561 & 0.062 & 0.852 & 164 & 0.775 & 0.049 & 0.926 & 497 & 0.798 & 0.037 & 0.958 & 931 \\
\hline 37 & 1.013 & 0.070 & 0.863 & 423 & 0.814 & 0.039 & 0.885 & 882 & 0.766 & 0.029 & 0.915 & 1,391 \\
\hline 38 & 0.585 & 0.084 & 0.837 & 98 & 0.577 & 0.059 & 0.961 & 194 & 0.702 & 0.067 & 0.901 & 221 \\
\hline 39 & 1.077 & 0.150 & 0.893 & 103 & 0.923 & 0.101 & 0.858 & 166 & 0.775 & 0.074 & 0.948 & 220 \\
\hline 40 & 0.762 & 0.066 & 0.846 & 267 & 0.644 & 0.040 & 0.912 & 511 & 0.532 & 0.030 & 0.971 & 626 \\
\hline 41 & 0.529 & 0.076 & 0.859 & 98 & 0.633 & 0.060 & 0.939 & 225 & 0.615 & 0.050 & 0.964 & 304 \\
\hline 42 & 0.661 & 0.091 & 0.806 & 105 & 0.568 & 0.061 & 0.815 & 176 & 0.507 & 0.045 & 0.793 & 254 \\
\hline 43 & 0.738 & 0.085 & 0.926 & 152 & 0.678 & 0.050 & 0.937 & 372 & 0.736 & 0.057 & 0.951 & 338 \\
\hline 44 & 0.702 & 0.053 & 0.818 & 353 & 0.719 & 0.037 & 0.924 & 756 & 0.683 & 0.029 & 0.895 & 1,080 \\
\hline 45 & 0.757 & 0.079 & 0.912 & 185 & 0.602 & 0.044 & 0.915 & 376 & 0.565 & 0.039 & 0.909 & 426 \\
\hline 46 & 0.868 & 0.083 & 0.804 & 217 & 0.703 & 0.051 & 0.901 & 385 & 0.588 & 0.039 & 0.927 & 461 \\
\hline 47 & 0.645 & 0.062 & 0.919 & 214 & 0.649 & 0.049 & 0.927 & 356 & 0.444 & 0.032 & 0.893 & 382 \\
\hline 48 & 0.851 & 0.067 & 0.935 & 321 & 0.806 & 0.041 & 0.954 & 785 & 0.725 & 0.031 & 0.967 & 1,102 \\
\hline 49 & 0.580 & 0.059 & 0.801 & 194 & 0.556 & 0.038 & 0.949 & 432 & 0.671 & 0.045 & 0.972 & 451 \\
\hline 50 & 0.657 & 0.073 & 0.886 & 164 & 0.650 & 0.056 & 0.927 & 274 & 0.579 & 0.041 & 0.897 & 398 \\
\hline 51 & 0.848 & 0.061 & 0.874 & 391 & 0.692 & 0.035 & 0.911 & 794 & 0.663 & 0.028 & 0.875 & 1,134 \\
\hline 52 & 0.682 & 0.076 & 0.817 & 163 & 0.618 & 0.053 & 0.906 & 272 & 0.537 & 0.040 & 0.911 & 358 \\
\hline 53 & 0.593 & 0.085 & 0.774 & 98 & 0.676 & 0.057 & 0.916 & 281 & 0.796 & 0.050 & 0.955 & 509 \\
\hline 55 & 1.732 & 0.099 & 0.885 & 608 & 1.567 & 0.054 & 0.905 & 1,672 & 1.322 & 0.035 & 0.932 & 2,893 \\
\hline 56 & 2.250 & 0.109 & 0.930 & 848 & 2.372 & 0.068 & 0.931 & 2,470 & 2.336 & 0.052 & 0.942 & 3,965 \\
\hline 57 & 0.731 & 0.082 & 0.881 & 160 & 0.752 & 0.061 & 0.918 & 301 & 0.648 & 0.055 & 0.915 & 276 \\
\hline 58 & 0.578 & 0.077 & 0.804 & 114 & 0.530 & 0.048 & 0.746 & 247 & 0.462 & 0.037 & 0.801 & 308 \\
\hline 59 & 0.696 & 0.071 & 0.893 & 191 & 0.661 & 0.046 & 0.932 & 418 & 0.561 & 0.035 & 0.921 & 527 \\
\hline 60 & 0.934 & 0.063 & 0.840 & 445 & 0.981 & 0.037 & 0.928 & 1,381 & 0.836 & 0.024 & 0.934 & 2,378 \\
\hline 61 & 0.863 & 0.069 & 0.855 & 312 & 0.648 & 0.040 & 0.899 & 529 & 0.622 & 0.033 & 0.922 & 712 \\
\hline 62 & 1.206 & 0.073 & 0.873 & 541 & 1.139 & 0.042 & 0.934 & 1,485 & 0.959 & 0.028 & 0.938 & 2,423 \\
\hline
\end{tabular}




\begin{tabular}{|c|c|c|c|c|c|c|c|c|c|c|c|c|}
\hline \multirow{2}{*}{$\begin{array}{c}\text { Table B2 } \\
\text { country }\end{array}$} & \multicolumn{4}{|c|}{ 2-digit trade flows } & \multicolumn{4}{|c|}{ 3-digit trade flows } & \multicolumn{4}{|c|}{ 4-digit trade flows } \\
\hline & estimate & st error & fit & \# obs & estimate & st error & fit & \# obs & estimate & st error & fit & \# obs \\
\hline 63 & 1.007 & 0.075 & 0.826 & 361 & 0.938 & 0.047 & 0.923 & 811 & 0.827 & 0.029 & 0.944 & 1,595 \\
\hline 64 & 0.974 & 0.071 & 0.947 & 374 & 1.162 & 0.052 & 0.969 & 984 & 1.025 & 0.037 & 0.974 & 1,545 \\
\hline 65 & 0.917 & 0.094 & 0.790 & 191 & 0.785 & 0.053 & 0.832 & 433 & 0.862 & 0.046 & 0.966 & 700 \\
\hline 66 & 1.666 & 0.115 & 0.930 & 419 & 1.358 & 0.054 & 0.963 & 1,279 & 1.166 & 0.033 & 0.969 & 2,452 \\
\hline 67 & 0.842 & 0.061 & 0.870 & 377 & 0.734 & 0.041 & 0.905 & 631 & 0.646 & 0.030 & 0.911 & 907 \\
\hline 68 & 0.866 & 0.065 & 0.845 & 356 & 0.830 & 0.040 & 0.846 & 841 & 0.683 & 0.025 & 0.944 & 1,459 \\
\hline 69 & 1.033 & 0.065 & 0.893 & 506 & 0.881 & 0.036 & 0.910 & 1,170 & 0.736 & 0.023 & 0.907 & 1,991 \\
\hline 70 & 1.222 & 0.162 & 0.897 & 114 & 1.173 & 0.091 & 0.909 & 329 & 1.031 & 0.060 & 0.960 & 601 \\
\hline 72 & 1.036 & 0.071 & 0.910 & 429 & 1.124 & 0.047 & 0.965 & 1,131 & 0.925 & 0.032 & 0.970 & 1,670 \\
\hline 73 & 0.985 & 0.067 & 0.963 & 435 & 1.061 & 0.046 & 0.982 & 1,044 & 0.899 & 0.030 & 0.970 & 1,757 \\
\hline 74 & 0.988 & 0.064 & 0.920 & 472 & 1.009 & 0.041 & 0.964 & 1,205 & 0.919 & 0.029 & 0.981 & 2,057 \\
\hline 75 & 0.952 & 0.072 & 0.897 & 354 & 0.834 & 0.043 & 0.942 & 755 & 0.784 & 0.031 & 0.950 & 1,283 \\
\hline 76 & 0.884 & 0.060 & 0.869 & 437 & 0.878 & 0.041 & 0.945 & 901 & 0.844 & 0.033 & 0.954 & 1,344 \\
\hline 78 & 1.012 & 0.109 & 0.857 & 173 & 0.824 & 0.062 & 0.914 & 357 & 0.716 & 0.049 & 0.919 & 424 \\
\hline 79 & 0.928 & 0.067 & 0.935 & 379 & 0.947 & 0.042 & 0.934 & 995 & 0.897 & 0.035 & 0.947 & 1,345 \\
\hline 80 & 0.834 & 0.089 & 0.908 & 176 & 0.734 & 0.054 & 0.904 & 366 & 0.616 & 0.047 & 0.953 & 346 \\
\hline 81 & 0.719 & 0.073 & 0.906 & 192 & 0.792 & 0.054 & 0.928 & 427 & 0.654 & 0.035 & 0.912 & 686 \\
\hline 82 & 0.882 & 0.069 & 0.918 & 327 & 0.837 & 0.045 & 0.890 & 702 & 0.765 & 0.032 & 0.913 & 1,144 \\
\hline 83 & 0.639 & 0.068 & 0.722 & 175 & 0.737 & 0.049 & 0.881 & 456 & 0.773 & 0.040 & 0.957 & 734 \\
\hline 84 & 0.976 & 0.072 & 0.866 & 364 & 0.878 & 0.041 & 0.921 & 908 & 0.768 & 0.031 & 0.889 & 1,229 \\
\hline 85 & 0.824 & 0.072 & 0.898 & 264 & 0.866 & 0.049 & 0.969 & 613 & 0.801 & 0.034 & 0.983 & 1,078 \\
\hline 86 & 0.968 & 0.151 & 0.790 & 82 & 0.759 & 0.075 & 0.892 & 207 & 0.647 & 0.050 & 0.739 & 330 \\
\hline 87 & 1.036 & 0.078 & 0.933 & 351 & 0.887 & 0.043 & 0.943 & 858 & 0.832 & 0.034 & 0.961 & 1,229 \\
\hline 88 & 1.118 & 0.117 & 0.825 & 184 & 1.024 & 0.068 & 0.915 & 449 & 0.813 & 0.043 & 0.926 & 721 \\
\hline 89 & 0.605 & 0.086 & 0.853 & 98 & 0.586 & 0.057 & 0.927 & 208 & 0.738 & 0.073 & 0.950 & 206 \\
\hline 91 & 0.820 & 0.070 & 0.936 & 278 & 0.823 & 0.045 & 0.954 & 678 & 0.731 & 0.032 & 0.957 & 1,052 \\
\hline 92 & 0.636 & 0.073 & 0.852 & 153 & 0.621 & 0.050 & 0.942 & 307 & 0.584 & 0.044 & 0.951 & 356 \\
\hline 93 & 0.735 & 0.075 & 0.880 & 193 & 0.661 & 0.046 & 0.927 & 405 & 0.650 & 0.042 & 0.943 & 483 \\
\hline 94 & 0.664 & 0.058 & 0.861 & 263 & 0.615 & 0.041 & 0.853 & 454 & 0.605 & 0.034 & 0.945 & 644 \\
\hline 95 & 0.919 & 0.063 & 0.899 & 421 & 0.908 & 0.043 & 0.946 & 884 & 0.824 & 0.032 & 0.974 & 1,294 \\
\hline
\end{tabular}




\begin{tabular}{|c|c|c|c|c|c|c|c|c|c|c|c|c|}
\hline \multirow{2}{*}{$\begin{array}{l}\text { Table B2 } \\
\text { country }\end{array}$} & \multicolumn{4}{|c|}{ 2-digit trade flows } & \multicolumn{4}{|c|}{ 3-digit trade flows } & \multicolumn{4}{|c|}{ 4-digit trade flows } \\
\hline & estimate & st error & fit & \# obs & estimate & st error & fit & \# obs & estimate & st error & fit & \# obs \\
\hline 96 & 0.864 & 0.079 & 0.914 & 237 & 0.656 & 0.050 & 0.879 & 344 & 0.555 & 0.037 & 0.936 & 451 \\
\hline 98 & 1.377 & 0.091 & 0.948 & 462 & 1.256 & 0.049 & 0.973 & 1,333 & 1.115 & 0.033 & 0.972 & 2,339 \\
\hline 99 & 2.557 & 0.173 & 0.919 & 436 & 2.229 & 0.073 & 0.923 & 1,886 & 1.973 & 0.055 & 0.908 & 2,594 \\
\hline 100 & 0.924 & 0.116 & 0.971 & 127 & 0.927 & 0.072 & 0.948 & 334 & 0.870 & 0.051 & 0.969 & 593 \\
\hline 101 & 1.062 & 0.071 & 0.928 & 449 & 1.023 & 0.043 & 0.937 & 1,137 & 0.822 & 0.026 & 0.955 & 1,945 \\
\hline 102 & 1.021 & 0.138 & 0.922 & 109 & 1.034 & 0.092 & 0.898 & 251 & 1.004 & 0.069 & 0.938 & 424 \\
\hline 103 & 0.762 & 0.118 & 0.911 & 84 & 0.792 & 0.080 & 0.920 & 196 & 0.766 & 0.058 & 0.975 & 348 \\
\hline 104 & 0.837 & 0.059 & 0.954 & 403 & 0.835 & 0.036 & 0.986 & 1,078 & 0.879 & 0.031 & 0.948 & 1,631 \\
\hline 105 & 1.100 & 0.134 & 0.925 & 135 & 1.028 & 0.076 & 0.940 & 368 & 0.940 & 0.062 & 0.960 & 453 \\
\hline 106 & 1.240 & 0.073 & 0.980 & 575 & 1.107 & 0.040 & 0.956 & 1,528 & 0.939 & 0.027 & 0.958 & 2,368 \\
\hline 107 & 0.817 & 0.141 & 0.911 & 67 & 0.899 & 0.094 & 0.955 & 183 & 1.153 & 0.118 & 0.968 & 192 \\
\hline 108 & 0.997 & 0.137 & 0.840 & 106 & 1.011 & 0.103 & 0.886 & 192 & 0.833 & 0.097 & 0.899 & 148 \\
\hline 109 & 1.025 & 0.163 & 0.874 & 79 & 1.033 & 0.103 & 0.880 & 200 & 1.094 & 0.102 & 0.943 & 229 \\
\hline 110 & 1.237 & 0.245 & 0.904 & 51 & 1.119 & 0.145 & 0.889 & 119 & 1.033 & 0.101 & 0.889 & 210 \\
\hline 111 & 1.055 & 0.097 & 0.953 & 235 & 0.984 & 0.056 & 0.943 & 627 & 0.903 & 0.042 & 0.966 & 914 \\
\hline 112 & 0.965 & 0.131 & 0.880 & 108 & 1.033 & 0.083 & 0.947 & 308 & 1.004 & 0.080 & 0.982 & 314 \\
\hline 113 & 1.142 & 0.078 & 0.919 & 431 & 1.110 & 0.042 & 0.910 & 1,417 & 0.965 & 0.026 & 0.942 & 2,792 \\
\hline 114 & 0.831 & 0.121 & 0.895 & 95 & 0.717 & 0.074 & 0.925 & 186 & 0.637 & 0.060 & 0.958 & 224 \\
\hline 115 & 1.037 & 0.151 & 0.887 & 94 & 0.982 & 0.098 & 0.865 & 199 & 0.804 & 0.069 & 0.883 & 270 \\
\hline 117 & 0.727 & 0.070 & 0.894 & 216 & 0.712 & 0.048 & 0.881 & 435 & 0.635 & 0.035 & 0.890 & 656 \\
\hline 118 & 0.848 & 0.086 & 0.689 & 195 & 0.521 & 0.035 & 0.932 & 451 & 0.681 & 0.036 & 0.954 & 710 \\
\hline 119 & 0.801 & 0.084 & 0.918 & 181 & 0.629 & 0.048 & 0.939 & 350 & 0.628 & 0.046 & 0.943 & 375 \\
\hline 120 & 0.702 & 0.135 & 0.797 & 54 & 0.684 & 0.108 & 0.793 & 80 & 1.170 & 0.194 & 0.921 & 73 \\
\hline 121 & 0.958 & 0.077 & 0.886 & 309 & 0.724 & 0.040 & 0.912 & 668 & 0.611 & 0.028 & 0.910 & 968 \\
\hline 122 & 0.750 & 0.062 & 0.889 & 296 & 0.759 & 0.042 & 0.941 & 653 & 0.681 & 0.035 & 0.954 & 770 \\
\hline 123 & 0.837 & 0.068 & 0.885 & 301 & 0.677 & 0.034 & 0.949 & 787 & 0.780 & 0.031 & 0.952 & 1,254 \\
\hline 124 & 1.331 & 0.086 & 0.929 & 477 & 1.223 & 0.042 & 0.918 & 1,677 & 1.086 & 0.030 & 0.888 & 2,642 \\
\hline 125 & 1.362 & 0.081 & 0.881 & 570 & 1.017 & 0.036 & 0.918 & 1,606 & 0.959 & 0.026 & 0.920 & 2,665 \\
\hline 126 & 1.129 & 0.085 & 0.877 & 354 & 1.107 & 0.053 & 0.934 & 883 & 1.135 & 0.041 & 0.973 & 1,543 \\
\hline 127 & 1.347 & 0.089 & 0.917 & 458 & 1.291 & 0.045 & 0.937 & 1,680 & 1.189 & 0.032 & 0.950 & 2,729 \\
\hline
\end{tabular}




\begin{tabular}{|c|c|c|c|c|c|c|c|c|c|c|c|c|}
\hline \multirow{2}{*}{$\begin{array}{c}\text { Table B2 } \\
\text { country }\end{array}$} & \multicolumn{4}{|c|}{ 2-digit trade flows } & \multicolumn{4}{|c|}{ 3-digit trade flows } & \multicolumn{4}{|c|}{ 4-digit trade flows } \\
\hline & estimate & st error & fit & \# obs & estimate & st error & fit & \# obs & estimate & st error & fit & \# obs \\
\hline 128 & 0.726 & 0.081 & 0.907 & 160 & 0.748 & 0.055 & 0.924 & 366 & 0.649 & 0.040 & 0.914 & 525 \\
\hline 129 & 0.859 & 0.070 & 0.858 & 305 & 0.889 & 0.044 & 0.936 & 822 & 0.921 & 0.039 & 0.946 & 1,123 \\
\hline 130 & 0.626 & 0.090 & 0.832 & 96 & 0.571 & 0.049 & 0.857 & 267 & 0.576 & 0.044 & 0.876 & 347 \\
\hline 131 & 1.003 & 0.083 & 0.911 & 295 & 0.595 & 0.035 & 0.948 & 570 & 0.591 & 0.030 & 0.936 & 777 \\
\hline 132 & 0.980 & 0.079 & 0.812 & 304 & 0.900 & 0.040 & 0.925 & 1,007 & 0.772 & 0.028 & 0.885 & 1,507 \\
\hline 133 & 1.067 & 0.069 & 0.907 & 480 & 0.970 & 0.042 & 0.920 & 1,089 & 0.868 & 0.029 & 0.962 & 1,783 \\
\hline 134 & 1.343 & 0.096 & 0.980 & 393 & 1.328 & 0.053 & 0.979 & 1,245 & 1.420 & 0.046 & 0.964 & 1,948 \\
\hline 135 & 1.206 & 0.072 & 0.918 & 558 & 1.026 & 0.037 & 0.975 & 1,510 & 1.025 & 0.029 & 0.972 & 2,484 \\
\hline 136 & 1.386 & 0.087 & 0.926 & 503 & 1.392 & 0.047 & 0.907 & 1,778 & 1.287 & 0.034 & 0.911 & 2,856 \\
\hline 137 & 1.850 & 0.099 & 0.948 & 705 & 1.317 & 0.039 & 0.960 & 2,245 & 1.093 & 0.024 & 0.945 & 4,064 \\
\hline 138 & 1.105 & 0.074 & 0.955 & 451 & 0.818 & 0.034 & 0.949 & 1,145 & 0.756 & 0.027 & 0.938 & 1,616 \\
\hline 139 & 0.727 & 0.075 & 0.806 & 186 & 0.647 & 0.047 & 0.867 & 377 & 0.565 & 0.035 & 0.918 & 536 \\
\hline 140 & 0.957 & 0.066 & 0.882 & 415 & 0.870 & 0.037 & 0.924 & 1,124 & 0.846 & 0.031 & 0.947 & 1,464 \\
\hline 142 & 2.807 & 0.143 & 0.945 & 769 & 2.114 & 0.060 & 0.954 & 2,521 & 1.888 & 0.041 & 0.944 & 4,195 \\
\hline 143 & 1.441 & 0.074 & 0.904 & 763 & 1.325 & 0.039 & 0.981 & 2,313 & 1.197 & 0.028 & 0.962 & 3,732 \\
\hline 144 & 2.373 & 0.115 & 0.981 & 859 & 2.421 & 0.062 & 0.968 & 3,085 & 2.330 & 0.047 & 0.983 & 4,993 \\
\hline 145 & 3.710 & 0.190 & 0.874 & 759 & 3.326 & 0.087 & 0.907 & 2,942 & 2.948 & 0.059 & 0.900 & 5,075 \\
\hline 146 & 1.293 & 0.077 & 0.919 & 559 & 1.074 & 0.039 & 0.916 & 1,546 & 0.973 & 0.026 & 0.937 & 2,817 \\
\hline 147 & 1.311 & 0.072 & 0.947 & 662 & 1.253 & 0.042 & 0.939 & 1,810 & 1.245 & 0.032 & 0.954 & 2,979 \\
\hline 148 & 2.149 & 0.121 & 0.937 & 626 & 2.064 & 0.058 & 0.940 & 2,567 & 1.765 & 0.037 & 0.960 & 4,455 \\
\hline 149 & 1.777 & 0.088 & 0.918 & 815 & 1.779 & 0.050 & 0.930 & 2,510 & 1.542 & 0.032 & 0.944 & 4,529 \\
\hline 150 & 1.234 & 0.074 & 0.860 & 553 & 1.061 & 0.036 & 0.969 & 1,708 & 1.045 & 0.027 & 0.913 & 2,960 \\
\hline 151 & 1.704 & 0.093 & 0.946 & 676 & 1.467 & 0.043 & 0.982 & 2,280 & 1.417 & 0.032 & 0.979 & 4,010 \\
\hline 152 & 2.829 & 0.150 & 0.954 & 715 & 2.586 & 0.070 & 0.953 & 2,711 & 2.475 & 0.055 & 0.972 & 4,037 \\
\hline 154 & 2.111 & 0.110 & 0.966 & 732 & 1.937 & 0.053 & 0.966 & 2,690 & 1.647 & 0.036 & 0.950 & 4,184 \\
\hline 155 & 1.132 & 0.075 & 0.894 & 455 & 1.340 & 0.048 & 0.951 & 1,582 & 1.095 & 0.029 & 0.921 & 2,757 \\
\hline 156 & 0.643 & 0.059 & 0.855 & 239 & 0.588 & 0.037 & 0.883 & 501 & 0.559 & 0.029 & 0.873 & 745 \\
\hline 157 & 1.328 & 0.084 & 0.899 & 503 & 1.134 & 0.047 & 0.929 & 1,144 & 1.124 & 0.035 & 0.921 & 2,093 \\
\hline 158 & 1.787 & 0.102 & 0.962 & 615 & 2.006 & 0.064 & 0.968 & 1,961 & 1.420 & 0.034 & 0.951 & 3,506 \\
\hline 159 & 1.569 & 0.091 & 0.917 & 597 & 1.458 & 0.045 & 0.934 & 2,076 & 1.362 & 0.034 & 0.957 & 3,196 \\
\hline
\end{tabular}




\begin{tabular}{|c|c|c|c|c|c|c|c|c|c|c|c|c|}
\hline \multirow{2}{*}{$\begin{array}{l}\text { Table B2 } \\
\text { country }\end{array}$} & \multicolumn{4}{|c|}{ 2-digit trade flows } & \multicolumn{4}{|c|}{ 3-digit trade flows } & \multicolumn{4}{|c|}{ 4-digit trade flows } \\
\hline & estimate & st error & fit & \# obs & estimate & st error & fit & \# obs & estimate & st error & fit & \# obs \\
\hline 161 & 1.171 & 0.095 & 0.979 & 302 & 0.962 & 0.049 & 0.976 & 786 & 0.998 & 0.048 & 0.975 & 875 \\
\hline 162 & 1.218 & 0.092 & 0.916 & 349 & 0.952 & 0.042 & 0.922 & 1,030 & 0.757 & 0.028 & 0.928 & 1,497 \\
\hline 164 & 0.807 & 0.056 & 0.916 & 416 & 0.840 & 0.038 & 0.932 & 984 & 0.752 & 0.027 & 0.936 & 1,505 \\
\hline 165 & 1.266 & 0.085 & 0.985 & 439 & 1.312 & 0.051 & 0.978 & 1,329 & 1.144 & 0.035 & 0.966 & 2,117 \\
\hline 166 & 1.845 & 0.105 & 0.957 & 622 & 1.542 & 0.046 & 0.972 & 2,237 & 1.493 & 0.042 & 0.989 & 2,492 \\
\hline 167 & 1.158 & 0.116 & 0.970 & 200 & 1.469 & 0.077 & 0.992 & 731 & 1.205 & 0.057 & 0.984 & 886 \\
\hline 168 & 2.033 & 0.103 & 0.941 & 784 & 1.377 & 0.040 & 0.982 & 2,320 & 1.248 & 0.035 & 0.979 & 2,594 \\
\hline 169 & 1.470 & 0.089 & 0.964 & 545 & 1.240 & 0.042 & 0.969 & 1,771 & 1.226 & 0.034 & 0.957 & 2,582 \\
\hline 170 & 1.306 & 0.096 & 0.982 & 373 & 1.445 & 0.059 & 0.973 & 1,193 & 1.346 & 0.041 & 0.970 & 2,119 \\
\hline 172 & 1.981 & 0.101 & 0.942 & 774 & 1.769 & 0.050 & 0.952 & 2,544 & 1.345 & 0.028 & 0.981 & 4,515 \\
\hline 173 & 1.403 & 0.100 & 0.905 & 391 & 1.340 & 0.060 & 0.929 & 1,003 & 1.248 & 0.049 & 0.923 & 1,293 \\
\hline 174 & 1.070 & 0.074 & 0.798 & 420 & 0.983 & 0.040 & 0.916 & 1,205 & 0.964 & 0.029 & 0.910 & 2,238 \\
\hline 175 & 0.970 & 0.062 & 0.827 & 482 & 0.834 & 0.036 & 0.899 & 1,057 & 0.798 & 0.024 & 0.946 & 2,134 \\
\hline 176 & 0.624 & 0.073 & 0.654 & 148 & 0.555 & 0.048 & 0.806 & 263 & 0.506 & 0.042 & 0.806 & 288 \\
\hline 177 & 0.661 & 0.061 & 0.903 & 234 & 0.822 & 0.047 & 0.959 & 611 & 0.711 & 0.034 & 0.953 & 888 \\
\hline 178 & 0.785 & 0.070 & 0.853 & 248 & 0.636 & 0.040 & 0.921 & 495 & 0.598 & 0.034 & 0.923 & 613 \\
\hline 179 & 0.884 & 0.087 & 0.795 & 205 & 0.601 & 0.045 & 0.900 & 353 & 0.469 & 0.033 & 0.839 & 410 \\
\hline 180 & 0.773 & 0.070 & 0.761 & 244 & 0.696 & 0.046 & 0.831 & 460 & 0.590 & 0.036 & 0.912 & 545 \\
\hline all & 0.955 & 0.006 & 0.968 & 53,503 & 0.928 & 0.003 & 0.991 & 142,231 & 0.869 & 0.003 & 0.991 & 221,430 \\
\hline
\end{tabular}


Table B3 GI slope estimates of Rank-Size rule; BI > 1, sector dimension ( $\gamma_{j}$ estimates)

\begin{tabular}{|c|c|c|c|c|c|c|c|c|c|}
\hline \multirow[b]{2}{*}{ sector } & \multicolumn{4}{|c|}{ 2-digit trade flows } & \multirow[b]{2}{*}{ sector } & \multicolumn{4}{|c|}{ 2-digit trade flows } \\
\hline & estimate & st error & fit & \# obs & & estimate & st error & fit & \# obs \\
\hline 01 & 1.048 & 0.052 & 0.873 & 797 & 58 & 2.301 & 0.170 & 0.950 & 365 \\
\hline 02 & 1.191 & 0.073 & 0.953 & 532 & 59 & 2.706 & 0.163 & 0.927 & 551 \\
\hline 03 & 0.787 & 0.025 & 0.903 & 2,024 & 61 & 1.064 & 0.046 & 0.925 & 1,078 \\
\hline 04 & 1.283 & 0.067 & 0.894 & 737 & 62 & 2.177 & 0.124 & 0.969 & 615 \\
\hline 05 & 0.999 & 0.033 & 0.884 & 1,866 & 63 & 1.366 & 0.058 & 0.946 & 1,109 \\
\hline 06 & 0.699 & 0.027 & 0.898 & 1,376 & 64 & 1.294 & 0.086 & 0.946 & 450 \\
\hline 07 & 0.646 & 0.022 & 0.764 & 1,710 & 65 & 1.472 & 0.065 & 0.956 & 1,032 \\
\hline 08 & 1.103 & 0.046 & 0.926 & 1,138 & 66 & 1.107 & 0.049 & 0.949 & 1,017 \\
\hline 09 & 1.334 & 0.061 & 0.978 & 957 & 67 & 1.696 & 0.089 & 0.970 & 722 \\
\hline 11 & 1.294 & 0.064 & 0.905 & 814 & 68 & 1.052 & 0.049 & 0.944 & 939 \\
\hline 12 & 0.904 & 0.038 & 0.967 & 1,122 & 69 & 2.156 & 0.117 & 0.981 & 678 \\
\hline 21 & 0.914 & 0.035 & 0.939 & 1,395 & 71 & 2.889 & 0.208 & 0.980 & 385 \\
\hline 22 & 0.796 & 0.036 & 0.891 & 980 & 72 & 2.581 & 0.182 & 0.983 & 403 \\
\hline 23 & 0.752 & 0.045 & 0.831 & 548 & 73 & 1.968 & 0.146 & 0.918 & 364 \\
\hline 24 & 0.926 & 0.038 & 0.901 & 1,177 & 74 & 3.005 & 0.212 & 0.924 & 401 \\
\hline 25 & 1.041 & 0.072 & 0.873 & 413 & 75 & 2.004 & 0.159 & 0.972 & 319 \\
\hline 26 & 0.752 & 0.028 & 0.895 & 1,443 & 76 & 2.020 & 0.140 & 0.904 & 417 \\
\hline 27 & 0.813 & 0.033 & 0.954 & 1,213 & 77 & 2.248 & 0.138 & 0.987 & 531 \\
\hline 28 & 0.777 & 0.031 & 0.863 & 1,260 & 78 & 3.113 & 0.254 & 0.925 & 301 \\
\hline 29 & 1.092 & 0.038 & 0.960 & 1,695 & 79 & 1.388 & 0.086 & 0.979 & 522 \\
\hline 32 & 0.984 & 0.073 & 0.864 & 366 & 81 & 2.108 & 0.114 & 0.982 & 687 \\
\hline 33 & 1.107 & 0.048 & 0.772 & 1,054 & 82 & 1.770 & 0.098 & 0.941 & 657 \\
\hline 34 & 0.908 & 0.064 & 0.886 & 404 & 83 & 1.259 & 0.069 & 0.909 & 668 \\
\hline 35 & 1.022 & 0.069 & 0.968 & 438 & 84 & 1.193 & 0.047 & 0.877 & 1,304 \\
\hline 41 & 0.977 & 0.062 & 0.944 & 494 & 85 & 1.366 & 0.070 & 0.887 & 758 \\
\hline 42 & 0.853 & 0.037 & 0.898 & 1,059 & 87 & 2.435 & 0.173 & 0.966 & 397 \\
\hline 43 & 1.256 & 0.074 & 0.972 & 580 & 88 & 1.461 & 0.106 & 0.911 & 379 \\
\hline 51 & 1.890 & 0.124 & 0.989 & 461 & 89 & 1.915 & 0.101 & 0.960 & 725 \\
\hline 52 & 0.966 & 0.049 & 0.967 & 781 & 93 & 1.170 & 0.059 & 0.965 & 779 \\
\hline 53 & 2.057 & 0.117 & 0.985 & 620 & 94 & 0.797 & 0.031 & 0.954 & 1,345 \\
\hline 54 & 1.405 & 0.073 & 0.967 & 744 & 95 & 1.456 & 0.146 & 0.891 & 199 \\
\hline 55 & 1.284 & 0.056 & 0.977 & 1,036 & 97 & 0.804 & 0.050 & 0.876 & 526 \\
\hline 56 & 1.124 & 0.054 & 0.954 & 862 & 99 & 0.808 & 0.041 & 0.800 & 784 \\
\hline all & 0.955 & 0.006 & 0.968 & 53,503 & & & & & \\
\hline Table B3 & & 3-digit tra & le flows & & & & -digit tra & flows & \\
\hline sector & estimate & st error & fit & \# obs & sector & estimate & st error & fit & $\#$ obs \\
\hline 001 & 0.862 & 0.041 & 0.977 & 880 & 653 & 1.631 & 0.094 & 0.920 & 607 \\
\hline 011 & 1.019 & 0.052 & 0.891 & 772 & 654 & 0.866 & 0.055 & 0.970 & 501 \\
\hline 012 & 0.869 & 0.072 & 0.941 & 295 & 655 & 1.545 & 0.096 & 0.917 & 517 \\
\hline 014 & 1.024 & 0.056 & 0.913 & 680 & 656 & 1.362 & 0.080 & 0.970 & 576 \\
\hline 022 & 1.201 & 0.082 & 0.951 & 433 & 657 & 1.586 & 0.083 & 0.987 & 727 \\
\hline 023 & 0.857 & 0.063 & 0.909 & 375 & 658 & 1.141 & 0.048 & 0.981 & 1,154 \\
\hline
\end{tabular}




\begin{tabular}{|c|c|c|c|c|c|c|c|c|c|}
\hline \multirow{2}{*}{$\begin{array}{l}\text { Table B3 } \\
\text { sector }\end{array}$} & \multicolumn{4}{|c|}{ 3-digit trade flows } & \multirow[b]{2}{*}{ sector } & \multicolumn{4}{|c|}{ 3-digit trade flows } \\
\hline & estimate & st error & fit & \# obs & & estimate & st error & fit & \# obs \\
\hline 024 & 1.204 & 0.075 & 0.887 & 521 & 659 & 0.884 & 0.047 & 0.970 & 708 \\
\hline 025 & 1.081 & 0.065 & 0.922 & 560 & 661 & 1.096 & 0.048 & 0.933 & 1,027 \\
\hline 034 & 0.736 & 0.028 & 0.938 & 1,399 & 662 & 1.626 & 0.106 & 0.915 & 471 \\
\hline 035 & 0.722 & 0.031 & 0.961 & 1,069 & 663 & 1.921 & 0.121 & 0.990 & 500 \\
\hline 036 & 0.730 & 0.024 & 0.913 & 1,801 & 665 & 2.241 & 0.127 & 0.942 & 625 \\
\hline 037 & 0.758 & 0.031 & 0.944 & 1,163 & 666 & 1.684 & 0.099 & 0.947 & 580 \\
\hline 041 & 1.211 & 0.104 & 0.861 & 269 & 667 & 0.800 & 0.041 & 0.878 & 750 \\
\hline 042 & 0.606 & 0.033 & 0.816 & 668 & 671 & 0.737 & 0.039 & 0.954 & 724 \\
\hline 043 & 1.238 & 0.095 & 0.883 & 336 & 672 & 1.189 & 0.067 & 0.977 & 630 \\
\hline 044 & 1.061 & 0.075 & 0.904 & 399 & 673 & 1.519 & 0.085 & 0.969 & 634 \\
\hline 045 & 0.878 & 0.064 & 0.981 & 374 & 674 & 1.983 & 0.129 & 0.913 & 471 \\
\hline 046 & 0.987 & 0.061 & 0.951 & 522 & 676 & 1.219 & 0.089 & 0.968 & 372 \\
\hline 047 & 1.139 & 0.066 & 0.958 & 594 & 677 & 1.711 & 0.104 & 0.977 & 541 \\
\hline 048 & 1.487 & 0.070 & 0.981 & 908 & 678 & 2.395 & 0.160 & 0.975 & 450 \\
\hline 054 & 1.045 & 0.039 & 0.937 & 1,452 & 679 & 1.804 & 0.109 & 0.971 & 549 \\
\hline 056 & 1.186 & 0.055 & 0.936 & 932 & 681 & 1.009 & 0.065 & 0.928 & 475 \\
\hline 057 & 0.792 & 0.028 & 0.876 & 1,613 & 682 & 0.700 & 0.042 & 0.923 & 543 \\
\hline 058 & 1.102 & 0.044 & 0.936 & 1,247 & 683 & 0.852 & 0.068 & 0.945 & 314 \\
\hline 061 & 0.676 & 0.026 & 0.891 & 1,327 & 684 & 1.061 & 0.056 & 0.931 & 723 \\
\hline 062 & 1.413 & 0.065 & 0.963 & 954 & 685 & 0.777 & 0.048 & 0.909 & 525 \\
\hline 071 & 0.623 & 0.025 & 0.777 & 1,230 & 686 & 0.916 & 0.057 & 0.943 & 516 \\
\hline 073 & 0.633 & 0.029 & 0.895 & 959 & 689 & 0.693 & 0.044 & 0.926 & 501 \\
\hline 074 & 0.562 & 0.029 & 0.873 & 750 & 691 & 2.046 & 0.116 & 0.973 & 624 \\
\hline 075 & 0.656 & 0.025 & 0.964 & 1,364 & 692 & 1.647 & 0.078 & 0.995 & 882 \\
\hline 081 & 1.107 & 0.046 & 0.928 & 1,147 & 693 & 1.977 & 0.106 & 0.953 & 696 \\
\hline 091 & 1.072 & 0.061 & 0.959 & 624 & 694 & 2.139 & 0.147 & 0.926 & 421 \\
\hline 098 & 1.297 & 0.062 & 0.979 & 883 & 695 & 1.877 & 0.117 & 0.961 & 518 \\
\hline 111 & 1.186 & 0.064 & 0.982 & 686 & 696 & 1.977 & 0.122 & 0.915 & 528 \\
\hline 112 & 1.253 & 0.063 & 0.906 & 792 & 697 & 1.900 & 0.095 & 0.934 & 795 \\
\hline 121 & 0.756 & 0.034 & 0.960 & 1,005 & 699 & 1.375 & 0.081 & 0.955 & 583 \\
\hline 122 & 1.132 & 0.058 & 0.970 & 758 & 711 & 1.801 & 0.133 & 0.971 & 369 \\
\hline 211 & 0.926 & 0.036 & 0.930 & 1,351 & 712 & 1.636 & 0.140 & 0.979 & 273 \\
\hline 212 & 0.839 & 0.038 & 0.953 & 956 & 713 & 2.287 & 0.178 & 0.988 & 329 \\
\hline 222 & 0.801 & 0.043 & 0.905 & 683 & 714 & 1.631 & 0.125 & 0.981 & 340 \\
\hline 223 & 0.625 & 0.025 & 0.916 & 1,290 & 716 & 2.710 & 0.163 & 0.972 & 552 \\
\hline 232 & 0.664 & 0.042 & 0.767 & 497 & 718 & 1.355 & 0.097 & 0.971 & 391 \\
\hline 233 & 1.588 & 0.109 & 0.957 & 423 & 721 & 1.789 & 0.117 & 0.985 & 470 \\
\hline 244 & 0.659 & 0.076 & 0.765 & 152 & 722 & 1.959 & 0.151 & 0.957 & 336 \\
\hline 245 & 0.784 & 0.042 & 0.922 & 699 & 723 & 1.784 & 0.116 & 0.993 & 470 \\
\hline 246 & 0.870 & 0.055 & 0.964 & 507 & 724 & 1.575 & 0.138 & 0.921 & 260 \\
\hline 247 & 0.642 & 0.030 & 0.868 & 903 & 725 & 1.381 & 0.119 & 0.897 & 271 \\
\hline 248 & 1.118 & 0.050 & 0.891 & 1,013 & 726 & 1.467 & 0.133 & 0.935 & 243 \\
\hline 251 & 1.047 & 0.073 & 0.874 & 412 & 727 & 1.798 & 0.120 & 0.936 & 452 \\
\hline 261 & 0.605 & 0.053 & 0.863 & 264 & 728 & 2.400 & 0.181 & 0.954 & 353 \\
\hline
\end{tabular}




\begin{tabular}{|c|c|c|c|c|c|c|c|c|c|}
\hline \multirow{2}{*}{$\begin{array}{l}\text { Table B3 } \\
\text { sector }\end{array}$} & \multicolumn{4}{|c|}{ 3-digit trade flows } & \multirow[b]{2}{*}{ sector } & \multicolumn{4}{|c|}{ 3-digit trade flows } \\
\hline & estimate & st error & fit & \# obs & & estimate & st error & fit & $\#$ obs \\
\hline 263 & 0.645 & 0.027 & 0.889 & 1,153 & 736 & 1.924 & 0.144 & 0.909 & 357 \\
\hline 264 & 0.394 & 0.035 & 0.859 & 248 & 737 & 1.332 & 0.104 & 0.978 & 329 \\
\hline 265 & 0.620 & 0.038 & 0.828 & 535 & 741 & 2.543 & 0.172 & 0.970 & 438 \\
\hline 266 & 1.847 & 0.113 & 0.977 & 538 & 742 & 2.542 & 0.182 & 0.961 & 391 \\
\hline 268 & 0.555 & 0.037 & 0.880 & 457 & 743 & 2.555 & 0.194 & 0.901 & 348 \\
\hline 269 & 1.109 & 0.070 & 0.990 & 502 & 744 & 1.952 & 0.130 & 0.984 & 452 \\
\hline 271 & 0.439 & 0.030 & 0.839 & 436 & 745 & 1.633 & 0.138 & 0.913 & 281 \\
\hline 273 & 1.480 & 0.065 & 0.976 & 1,023 & 749 & 2.921 & 0.199 & 0.941 & 430 \\
\hline 274 & 0.852 & 0.067 & 0.921 & 326 & 751 & 1.869 & 0.146 & 0.921 & 326 \\
\hline 277 & 0.641 & 0.038 & 0.960 & 555 & 752 & 1.767 & 0.143 & 0.971 & 307 \\
\hline 278 & 0.994 & 0.044 & 0.909 & 1,008 & 759 & 1.536 & 0.143 & 0.956 & 232 \\
\hline 281 & 0.709 & 0.048 & 0.903 & 442 & 761 & 1.484 & 0.101 & 0.894 & 428 \\
\hline 282 & 1.288 & 0.072 & 0.986 & 646 & 762 & 1.270 & 0.100 & 0.839 & 324 \\
\hline 286 & 0.496 & 0.061 & 0.898 & 132 & 764 & 2.116 & 0.152 & 0.962 & 386 \\
\hline 287 & 0.661 & 0.028 & 0.863 & 1,132 & 771 & 1.953 & 0.118 & 0.972 & 551 \\
\hline 288 & 1.264 & 0.056 & 0.989 & 1,032 & 772 & 1.926 & 0.118 & 0.992 & 531 \\
\hline 289 & 0.723 & 0.046 & 0.935 & 490 & 773 & 1.549 & 0.084 & 0.973 & 676 \\
\hline 291 & 1.022 & 0.038 & 0.962 & 1,472 & 774 & 1.673 & 0.142 & 0.973 & 279 \\
\hline 292 & 1.054 & 0.038 & 0.962 & 1,507 & 775 & 2.343 & 0.143 & 0.955 & 534 \\
\hline 322 & 0.935 & 0.072 & 0.865 & 340 & 776 & 1.301 & 0.097 & 0.953 & 361 \\
\hline 323 & 0.963 & 0.076 & 0.958 & 325 & 778 & 2.625 & 0.165 & 0.984 & 504 \\
\hline 333 & 1.052 & 0.053 & 0.757 & 776 & 781 & 2.460 & 0.217 & 0.811 & 258 \\
\hline 334 & 1.067 & 0.043 & 0.924 & 1,206 & 782 & 1.977 & 0.158 & 0.949 & 314 \\
\hline 335 & 1.012 & 0.053 & 0.971 & 734 & 783 & 1.374 & 0.088 & 0.974 & 493 \\
\hline 341 & 0.909 & 0.064 & 0.885 & 404 & 784 & 3.420 & 0.277 & 0.906 & 304 \\
\hline 351 & 1.026 & 0.069 & 0.967 & 441 & 785 & 1.472 & 0.113 & 0.946 & 339 \\
\hline 411 & 0.983 & 0.062 & 0.943 & 498 & 786 & 1.823 & 0.113 & 0.984 & 524 \\
\hline 423 & 0.971 & 0.064 & 0.978 & 456 & 791 & 1.359 & 0.094 & 0.965 & 416 \\
\hline 424 & 0.788 & 0.034 & 0.890 & 1,085 & 792 & 1.498 & 0.130 & 0.943 & 267 \\
\hline 431 & 1.258 & 0.074 & 0.972 & 578 & 793 & 0.991 & 0.062 & 0.957 & 517 \\
\hline 511 & 1.949 & 0.135 & 0.965 & 417 & 812 & 2.105 & 0.113 & 0.977 & 688 \\
\hline 512 & 1.543 & 0.094 & 0.990 & 539 & 821 & 1.737 & 0.096 & 0.927 & 658 \\
\hline 513 & 1.384 & 0.094 & 0.901 & 432 & 831 & 1.240 & 0.068 & 0.902 & 669 \\
\hline 514 & 1.602 & 0.117 & 0.976 & 373 & 842 & 1.124 & 0.045 & 0.916 & 1,227 \\
\hline 515 & 1.282 & 0.087 & 0.954 & 430 & 843 & 1.177 & 0.048 & 0.927 & 1,191 \\
\hline 516 & 1.426 & 0.103 & 0.990 & 381 & 844 & 0.966 & 0.042 & 0.921 & 1,070 \\
\hline 522 & 0.907 & 0.046 & 0.962 & 778 & 845 & 1.219 & 0.054 & 0.934 & 1,031 \\
\hline 523 & 1.446 & 0.080 & 0.983 & 651 & 846 & 1.046 & 0.045 & 0.936 & 1,093 \\
\hline 524 & 0.690 & 0.065 & 0.916 & 225 & 847 & 1.223 & 0.056 & 0.946 & 941 \\
\hline 533 & 2.052 & 0.117 & 0.983 & 619 & 848 & 1.058 & 0.051 & 0.931 & 848 \\
\hline 541 & 1.357 & 0.070 & 0.980 & 744 & 851 & 1.332 & 0.068 & 0.881 & 759 \\
\hline 551 & 0.829 & 0.039 & 0.980 & 926 & 871 & 2.023 & 0.167 & 0.973 & 295 \\
\hline 553 & 1.425 & 0.076 & 0.945 & 712 & 872 & 1.646 & 0.119 & 0.975 & 384 \\
\hline 554 & 1.342 & 0.065 & 0.977 & 850 & 874 & 2.068 & 0.151 & 0.981 & 374 \\
\hline
\end{tabular}




\begin{tabular}{|c|c|c|c|c|c|c|c|c|c|}
\hline \multirow{2}{*}{$\begin{array}{l}\text { Table B3 } \\
\text { sector }\end{array}$} & \multicolumn{4}{|c|}{ 3-digit trade flows } & \multirow[b]{2}{*}{ sector } & \multicolumn{4}{|c|}{ 3-digit trade flows } \\
\hline & estimate & st error & fit & $\#$ obs & & estimate & st error & fit & \# obs \\
\hline 562 & 1.124 & 0.054 & 0.952 & 863 & 881 & 1.869 & 0.160 & 0.981 & 273 \\
\hline 582 & 2.151 & 0.178 & 0.950 & 291 & 882 & 2.462 & 0.202 & 0.955 & 298 \\
\hline 583 & 2.291 & 0.157 & 0.943 & 428 & 883 & 0.917 & 0.050 & 0.976 & 671 \\
\hline 584 & 2.120 & 0.150 & 0.982 & 399 & 884 & 1.316 & 0.096 & 0.966 & 376 \\
\hline 591 & 1.576 & 0.094 & 0.942 & 566 & 885 & 0.945 & 0.076 & 0.872 & 311 \\
\hline 592 & 1.312 & 0.077 & 0.972 & 581 & 892 & 1.618 & 0.087 & 0.984 & 696 \\
\hline 598 & 2.247 & 0.156 & 0.963 & 414 & 893 & 2.093 & 0.113 & 0.980 & 690 \\
\hline 611 & 0.919 & 0.043 & 0.920 & 924 & 894 & 1.189 & 0.076 & 0.947 & 492 \\
\hline 612 & 0.933 & 0.046 & 0.962 & 826 & 895 & 2.211 & 0.137 & 0.922 & 522 \\
\hline 613 & 0.956 & 0.058 & 0.914 & 547 & 896 & 1.083 & 0.065 & 0.970 & 561 \\
\hline 621 & 2.360 & 0.147 & 0.960 & 518 & 897 & 1.103 & 0.062 & 0.949 & 637 \\
\hline 625 & 2.030 & 0.116 & 0.946 & 609 & 898 & 1.690 & 0.124 & 0.988 & 373 \\
\hline 628 & 1.279 & 0.084 & 0.929 & 469 & 899 & 1.413 & 0.077 & 0.968 & 675 \\
\hline 634 & 1.134 & 0.052 & 0.945 & 956 & 931 & 1.177 & 0.060 & 0.962 & 776 \\
\hline 635 & 1.350 & 0.061 & 0.974 & 987 & 941 & 0.807 & 0.031 & 0.947 & 1,349 \\
\hline 641 & 1.072 & 0.090 & 0.898 & 286 & 951 & 1.457 & 0.146 & 0.891 & 199 \\
\hline 642 & 1.595 & 0.075 & 0.957 & 900 & 971 & 0.802 & 0.049 & 0.877 & 526 \\
\hline 651 & 1.346 & 0.062 & 0.962 & 940 & 999 & 0.808 & 0.041 & 0.799 & 777 \\
\hline 652 & 1.306 & 0.056 & 0.963 & 1,072 & all & 0.928 & 0.003 & 0.991 & 142,231 \\
\hline Table B3 & \multicolumn{4}{|c|}{ 4-digit trade flows } & & \multicolumn{4}{|c|}{ 4-digit trade flows } \\
\hline sector & estimate & st error & fit & \# obs & sector & estimate & st error & fit & \# obs \\
\hline 0011 & 0.873 & 0.049 & 0.966 & 640 & 6413 & 1.064 & 0.082 & 0.887 & 337 \\
\hline 0012 & 0.559 & 0.032 & 0.923 & 606 & 6415 & 1.264 & 0.087 & 0.965 & 426 \\
\hline 0013 & 1.017 & 0.092 & 0.887 & 243 & 6416 & 1.128 & 0.066 & 0.941 & 580 \\
\hline 0014 & 0.992 & 0.060 & 0.941 & 554 & 6417 & 1.246 & 0.078 & 0.960 & 517 \\
\hline 0015 & 0.940 & 0.062 & 0.948 & 466 & 6418 & 1.137 & 0.090 & 0.905 & 321 \\
\hline 0019 & 0.485 & 0.034 & 0.969 & 403 & 6419 & 1.658 & 0.120 & 0.955 & 380 \\
\hline 0111 & 0.846 & 0.045 & 0.853 & 705 & 6421 & 1.107 & 0.051 & 0.946 & 949 \\
\hline 0112 & 0.713 & 0.050 & 0.916 & 402 & 6424 & 1.743 & 0.089 & 0.966 & 773 \\
\hline 0113 & 1.154 & 0.090 & 0.930 & 327 & 6428 & 1.860 & 0.103 & 0.952 & 654 \\
\hline 0114 & 1.190 & 0.085 & 0.842 & 396 & 6512 & 1.098 & 0.062 & 0.946 & 626 \\
\hline 0115 & 0.818 & 0.060 & 0.878 & 366 & 6514 & 2.122 & 0.125 & 0.947 & 572 \\
\hline 0116 & 0.993 & 0.070 & 0.859 & 400 & 6517 & 1.596 & 0.100 & 0.958 & 511 \\
\hline 0118 & 0.869 & 0.044 & 0.948 & 770 & 6519 & 1.034 & 0.048 & 0.957 & 926 \\
\hline 0121 & 0.799 & 0.078 & 0.915 & 210 & 6521 & 0.952 & 0.044 & 0.925 & 932 \\
\hline 0129 & 0.836 & 0.052 & 0.986 & 519 & 6522 & 1.356 & 0.064 & 0.955 & 892 \\
\hline 0142 & 1.098 & 0.070 & 0.897 & 497 & 6531 & 1.457 & 0.089 & 0.912 & 539 \\
\hline 0149 & 1.003 & 0.055 & 0.921 & 659 & 6539 & 1.618 & 0.096 & 0.978 & 565 \\
\hline 0223 & 1.507 & 0.114 & 0.908 & 348 & 6542 & 1.134 & 0.078 & 0.951 & 419 \\
\hline 0224 & 1.119 & 0.075 & 0.954 & 444 & 6549 & 0.693 & 0.048 & 0.962 & 420 \\
\hline 0251 & 1.043 & 0.063 & 0.924 & 541 & 6552 & 0.764 & 0.057 & 0.984 & 359 \\
\hline 0252 & 1.155 & 0.076 & 0.937 & 460 & 6571 & 1.547 & 0.119 & 0.957 & 338 \\
\hline 0341 & 0.775 & 0.032 & 0.960 & 1,172 & 6573 & 1.943 & 0.137 & 0.933 & 404 \\
\hline 0342 & 0.728 & 0.029 & 0.939 & 1,276 & 6575 & 0.913 & 0.041 & 0.961 & 1,012 \\
\hline
\end{tabular}




\begin{tabular}{|c|c|c|c|c|c|c|c|c|c|}
\hline \multirow{2}{*}{$\begin{array}{l}\text { Table B3 } \\
\text { sector }\end{array}$} & \multicolumn{4}{|c|}{ 4-digit trade flows } & \multirow[b]{2}{*}{ sector } & \multicolumn{4}{|c|}{ 4-digit trade flows } \\
\hline & estimate & st error & fit & \# obs & & estimate & st error & fit & \# obs \\
\hline 0343 & 0.675 & 0.034 & 0.942 & 779 & 6577 & 1.604 & 0.106 & 0.966 & 457 \\
\hline 0344 & 0.604 & 0.030 & 0.947 & 822 & 6581 & 0.783 & 0.038 & 0.982 & 843 \\
\hline 0371 & 0.759 & 0.033 & 0.946 & 1,056 & 6583 & 1.054 & 0.052 & 0.865 & 820 \\
\hline 0372 & 0.727 & 0.036 & 0.978 & 802 & 6584 & 1.075 & 0.049 & 0.966 & 979 \\
\hline 0411 & 0.895 & 0.077 & 0.945 & 267 & 6589 & 1.364 & 0.065 & 0.968 & 872 \\
\hline 0412 & 1.124 & 0.107 & 0.847 & 222 & 6591 & 1.150 & 0.094 & 0.990 & 297 \\
\hline 0421 & 0.546 & 0.034 & 0.903 & 512 & 6592 & 0.869 & 0.047 & 0.967 & 683 \\
\hline 0422 & 0.617 & 0.036 & 0.838 & 585 & 6611 & 1.097 & 0.073 & 0.976 & 451 \\
\hline 0451 & 0.981 & 0.097 & 0.910 & 206 & 6612 & 0.900 & 0.038 & 0.907 & 1,102 \\
\hline 0452 & 0.936 & 0.082 & 0.888 & 263 & 6613 & 1.018 & 0.078 & 0.814 & 337 \\
\hline 0459 & 0.800 & 0.064 & 0.972 & 314 & 6618 & 1.380 & 0.072 & 0.993 & 734 \\
\hline 0481 & 0.932 & 0.056 & 0.958 & 561 & 6623 & 1.354 & 0.108 & 0.938 & 314 \\
\hline 0483 & 1.093 & 0.060 & 0.980 & 673 & 6624 & 1.440 & 0.098 & 0.917 & 436 \\
\hline 0484 & 1.472 & 0.074 & 0.973 & 788 & 6631 & 1.462 & 0.108 & 0.968 & 364 \\
\hline 0488 & 1.318 & 0.077 & 0.977 & 586 & 6632 & 1.924 & 0.144 & 0.904 & 358 \\
\hline 0541 & 0.787 & 0.042 & 0.965 & 686 & 6633 & 1.646 & 0.107 & 0.996 & 470 \\
\hline 0542 & 0.762 & 0.033 & 0.928 & 1,086 & 6638 & 1.870 & 0.121 & 0.975 & 476 \\
\hline 0544 & 0.700 & 0.047 & 0.900 & 437 & 6664 & 1.541 & 0.097 & 0.937 & 501 \\
\hline 0545 & 1.049 & 0.040 & 0.971 & 1,381 & 6665 & 1.521 & 0.103 & 0.950 & 433 \\
\hline 0546 & 1.225 & 0.065 & 0.923 & 717 & 6666 & 1.250 & 0.082 & 0.934 & 467 \\
\hline 0561 & 1.153 & 0.059 & 0.880 & 770 & 6672 & 0.746 & 0.043 & 0.850 & 591 \\
\hline 0565 & 1.118 & 0.054 & 0.935 & 851 & 6674 & 0.784 & 0.041 & 0.928 & 719 \\
\hline 0571 & 0.712 & 0.042 & 0.843 & 578 & 6712 & 0.896 & 0.062 & 0.930 & 412 \\
\hline 0572 & 0.778 & 0.043 & 0.902 & 653 & 6713 & 0.788 & 0.065 & 0.972 & 291 \\
\hline 0574 & 0.852 & 0.057 & 0.878 & 453 & 6716 & 0.652 & 0.037 & 0.944 & 623 \\
\hline 0575 & 0.688 & 0.044 & 0.913 & 485 & 6724 & 0.940 & 0.068 & 0.963 & 383 \\
\hline 0577 & 0.713 & 0.032 & 0.927 & 978 & 6725 & 1.172 & 0.067 & 0.980 & 606 \\
\hline 0579 & 0.656 & 0.025 & 0.906 & 1,421 & 6731 & 1.262 & 0.074 & 0.993 & 578 \\
\hline 0583 & 1.006 & 0.044 & 0.954 & 1,030 & 6732 & 1.482 & 0.083 & 0.977 & 639 \\
\hline 0585 & 0.983 & 0.043 & 0.985 & 1,043 & 6733 & 1.366 & 0.088 & 0.966 & 483 \\
\hline 0586 & 0.953 & 0.048 & 0.946 & 780 & 6748 & 1.192 & 0.146 & 0.960 & 133 \\
\hline 0589 & 0.965 & 0.046 & 0.868 & 870 & 6749 & 1.301 & 0.173 & 0.966 & 113 \\
\hline 0611 & 0.596 & 0.027 & 0.854 & 981 & 6781 & 1.407 & 0.110 & 0.946 & 326 \\
\hline 0612 & 0.884 & 0.044 & 0.938 & 818 & 6782 & 1.727 & 0.135 & 0.964 & 329 \\
\hline 0616 & 0.827 & 0.042 & 0.862 & 760 & 6783 & 2.024 & 0.127 & 0.970 & 505 \\
\hline 0619 & 0.790 & 0.033 & 0.883 & 1,161 & 6785 & 2.653 & 0.166 & 0.979 & 511 \\
\hline 0711 & 0.613 & 0.025 & 0.779 & 1,235 & 6793 & 1.446 & 0.112 & 0.977 & 335 \\
\hline 0712 & 0.793 & 0.051 & 0.896 & 480 & 6794 & 1.721 & 0.108 & 0.926 & 511 \\
\hline 0741 & 0.555 & 0.029 & 0.868 & 710 & 6811 & 0.864 & 0.052 & 0.928 & 545 \\
\hline 0742 & 0.531 & 0.068 & 0.681 & 121 & 6812 & 0.903 & 0.097 & 0.898 & 172 \\
\hline 0752 & 0.688 & 0.047 & 0.952 & 422 & 6821 & 0.604 & 0.039 & 0.907 & 486 \\
\hline 0811 & 1.175 & 0.073 & 0.965 & 519 & 6822 & 1.625 & 0.101 & 0.969 & 516 \\
\hline 0812 & 0.874 & 0.040 & 0.916 & 973 & 6831 & 0.762 & 0.062 & 0.923 & 304 \\
\hline 0813 & 0.921 & 0.045 & 0.904 & 826 & 6832 & 1.986 & 0.169 & 0.927 & 276 \\
\hline
\end{tabular}




\begin{tabular}{|c|c|c|c|c|c|c|c|c|c|}
\hline \multirow{2}{*}{$\begin{array}{l}\text { Table B3 } \\
\text { sector }\end{array}$} & \multicolumn{4}{|c|}{ 4-digit trade flows } & \multirow[b]{2}{*}{ sector } & \multicolumn{4}{|c|}{ 4-digit trade flows } \\
\hline & estimate & st error & fit & \# obs & & estimate & st error & fit & \# obs \\
\hline 0814 & 0.662 & 0.040 & 0.902 & 558 & 6841 & 0.814 & 0.048 & 0.876 & 568 \\
\hline 0819 & 1.612 & 0.092 & 0.984 & 617 & 6842 & 1.550 & 0.086 & 0.975 & 654 \\
\hline 1121 & 1.011 & 0.071 & 0.868 & 404 & 6851 & 0.752 & 0.048 & 0.893 & 496 \\
\hline 1123 & 1.218 & 0.069 & 0.923 & 623 & 6852 & 1.248 & 0.087 & 0.969 & 407 \\
\hline 1124 & 0.957 & 0.054 & 0.905 & 637 & 6861 & 0.884 & 0.056 & 0.932 & 494 \\
\hline 1211 & 0.694 & 0.032 & 0.951 & 922 & 6863 & 1.056 & 0.073 & 0.952 & 420 \\
\hline 1212 & 0.717 & 0.035 & 0.968 & 844 & 6899 & 0.725 & 0.089 & 0.980 & 134 \\
\hline 1213 & 0.746 & 0.039 & 0.974 & 748 & 6931 & 1.696 & 0.099 & 0.955 & 592 \\
\hline 1222 & 1.101 & 0.065 & 0.981 & 576 & 6935 & 1.461 & 0.080 & 0.952 & 675 \\
\hline 1223 & 0.815 & 0.045 & 0.917 & 661 & 6951 & 1.142 & 0.059 & 0.970 & 743 \\
\hline 2111 & 1.122 & 0.052 & 0.935 & 916 & 6953 & 1.589 & 0.104 & 0.989 & 463 \\
\hline 2112 & 0.866 & 0.048 & 0.962 & 659 & 6954 & 1.707 & 0.120 & 0.965 & 405 \\
\hline 2117 & 0.661 & 0.037 & 0.928 & 641 & 6973 & 1.497 & 0.085 & 0.941 & 613 \\
\hline 2119 & 0.655 & 0.024 & 0.912 & 1,539 & 6974 & 1.693 & 0.089 & 0.940 & 730 \\
\hline 2222 & 0.780 & 0.082 & 0.887 & 181 & 6991 & 2.004 & 0.140 & 0.898 & 411 \\
\hline 2223 & 0.505 & 0.031 & 0.900 & 522 & 6992 & 1.927 & 0.132 & 0.956 & 423 \\
\hline 2224 & 0.691 & 0.039 & 0.941 & 641 & 6996 & 2.129 & 0.115 & 0.956 & 682 \\
\hline 2225 & 0.503 & 0.030 & 0.896 & 548 & 6997 & 1.657 & 0.095 & 0.940 & 607 \\
\hline 2226 & 0.642 & 0.036 & 0.948 & 644 & 6998 & 1.851 & 0.110 & 0.992 & 564 \\
\hline 2232 & 0.455 & 0.029 & 0.871 & 501 & 6999 & 1.137 & 0.070 & 0.993 & 525 \\
\hline 2234 & 0.648 & 0.069 & 0.956 & 178 & 7133 & 1.699 & 0.139 & 0.884 & 298 \\
\hline 2235 & 0.587 & 0.044 & 0.815 & 361 & 7139 & 2.188 & 0.170 & 0.987 & 332 \\
\hline 2238 & 0.588 & 0.024 & 0.925 & 1,227 & 7149 & 1.404 & 0.190 & 0.968 & 109 \\
\hline 2331 & 1.552 & 0.109 & 0.951 & 408 & 7188 & 1.483 & 0.106 & 0.980 & 392 \\
\hline 2332 & 1.323 & 0.081 & 0.986 & 531 & 7211 & 1.688 & 0.101 & 0.963 & 560 \\
\hline 2471 & 0.943 & 0.067 & 0.946 & 400 & 7212 & 2.030 & 0.155 & 0.932 & 342 \\
\hline 2472 & 0.527 & 0.026 & 0.824 & 810 & 7213 & 0.890 & 0.078 & 0.840 & 260 \\
\hline 2479 & 0.589 & 0.039 & 0.968 & 448 & 7219 & 1.673 & 0.115 & 0.976 & 426 \\
\hline 2481 & 0.721 & 0.047 & 0.937 & 470 & 7234 & 1.512 & 0.181 & 0.996 & 140 \\
\hline 2482 & 1.098 & 0.071 & 0.838 & 472 & 7243 & 1.802 & 0.141 & 0.932 & 325 \\
\hline 2483 & 0.747 & 0.032 & 0.874 & 1,070 & 7247 & 1.413 & 0.130 & 0.931 & 237 \\
\hline 2511 & 1.732 & 0.110 & 0.978 & 495 & 7248 & 1.329 & 0.124 & 0.966 & 231 \\
\hline 2512 & 0.924 & 0.068 & 0.852 & 370 & 7251 & 1.061 & 0.092 & 0.944 & 266 \\
\hline 2516 & 0.902 & 0.085 & 0.909 & 227 & 7252 & 1.296 & 0.141 & 0.953 & 169 \\
\hline 2517 & 0.912 & 0.071 & 0.845 & 333 & 7259 & 1.403 & 0.116 & 0.935 & 294 \\
\hline 2518 & 0.982 & 0.082 & 0.774 & 290 & 7263 & 1.188 & 0.127 & 0.959 & 175 \\
\hline 2613 & 0.599 & 0.069 & 0.777 & 149 & 7269 & 1.161 & 0.120 & 0.969 & 187 \\
\hline 2614 & 0.684 & 0.051 & 0.919 & 357 & 7272 & 2.249 & 0.255 & 0.953 & 155 \\
\hline 2681 & 0.529 & 0.041 & 0.866 & 330 & 7281 & 1.733 & 0.151 & 0.903 & 264 \\
\hline 2682 & 0.621 & 0.044 & 0.916 & 395 & 7283 & 1.721 & 0.115 & 0.976 & 449 \\
\hline 2683 & 0.591 & 0.040 & 0.962 & 431 & 7284 & 2.426 & 0.192 & 0.910 & 319 \\
\hline 2685 & 0.708 & 0.046 & 0.927 & 470 & 7361 & 2.088 & 0.171 & 0.908 & 298 \\
\hline 2686 & 0.877 & 0.056 & 0.949 & 493 & 7369 & 1.748 & 0.146 & 0.986 & 288 \\
\hline 2731 & 1.087 & 0.054 & 0.909 & 814 & 7371 & 1.675 & 0.134 & 0.990 & 311 \\
\hline
\end{tabular}




\begin{tabular}{|c|c|c|c|c|c|c|c|c|c|}
\hline \multirow{2}{*}{$\begin{array}{l}\text { Table B3 } \\
\text { sector }\end{array}$} & \multicolumn{4}{|c|}{ 4-digit trade flows } & \multirow[b]{2}{*}{ sector } & \multicolumn{4}{|c|}{ 4-digit trade flows } \\
\hline & estimate & st error & fit & \# obs & & estimate & st error & fit & \# obs \\
\hline 2732 & 1.355 & 0.072 & 0.981 & 713 & 7413 & 1.595 & 0.113 & 0.981 & 399 \\
\hline 2733 & 1.162 & 0.078 & 0.948 & 444 & 7414 & 2.447 & 0.179 & 0.908 & 375 \\
\hline 2771 & 0.550 & 0.038 & 0.918 & 415 & 7416 & 2.177 & 0.169 & 0.934 & 331 \\
\hline 2772 & 1.011 & 0.072 & 0.961 & 399 & 7431 & 3.109 & 0.427 & 0.934 & 106 \\
\hline 2782 & 0.888 & 0.053 & 0.936 & 572 & 7441 & 1.907 & 0.150 & 0.981 & 323 \\
\hline 2783 & 0.842 & 0.041 & 0.967 & 835 & 7442 & 2.411 & 0.165 & 0.979 & 428 \\
\hline 2784 & 0.674 & 0.060 & 0.884 & 250 & 7451 & 1.502 & 0.135 & 0.963 & 249 \\
\hline 2785 & 0.826 & 0.049 & 0.886 & 559 & 7452 & 1.818 & 0.157 & 0.827 & 267 \\
\hline 2786 & 0.868 & 0.072 & 0.913 & 288 & 7491 & 2.131 & 0.163 & 0.893 & 341 \\
\hline 2789 & 0.982 & 0.047 & 0.956 & 877 & 7492 & 2.409 & 0.171 & 0.950 & 399 \\
\hline 2814 & 0.565 & 0.057 & 0.867 & 198 & 7493 & 2.246 & 0.177 & 0.957 & 323 \\
\hline 2815 & 0.639 & 0.046 & 0.908 & 386 & 7499 & 1.771 & 0.123 & 0.984 & 414 \\
\hline 2816 & 0.761 & 0.058 & 0.889 & 345 & 7511 & 1.710 & 0.130 & 0.941 & 346 \\
\hline 2871 & 0.636 & 0.041 & 0.924 & 474 & 7512 & 1.668 & 0.138 & 0.899 & 292 \\
\hline 2872 & 0.568 & 0.053 & 0.883 & 226 & 7591 & 1.519 & 0.149 & 0.954 & 209 \\
\hline 2873 & 0.415 & 0.030 & 0.789 & 392 & 7641 & 1.949 & 0.137 & 0.978 & 407 \\
\hline 2874 & 0.610 & 0.040 & 0.917 & 464 & 7642 & 1.649 & 0.127 & 0.968 & 335 \\
\hline 2875 & 0.632 & 0.041 & 0.921 & 474 & 7649 & 2.010 & 0.150 & 0.967 & 357 \\
\hline 2876 & 0.506 & 0.036 & 0.854 & 385 & 7721 & 1.847 & 0.208 & 0.964 & 158 \\
\hline 2879 & 0.708 & 0.033 & 0.922 & 902 & 7722 & 1.460 & 0.166 & 0.941 & 154 \\
\hline 2881 & 1.076 & 0.056 & 0.990 & 751 & 7731 & 1.482 & 0.081 & 0.974 & 668 \\
\hline 2882 & 1.253 & 0.055 & 0.986 & 1,021 & 7732 & 1.855 & 0.138 & 0.990 & 362 \\
\hline 2911 & 0.759 & 0.028 & 0.947 & 1,463 & 7742 & 1.615 & 0.147 & 0.971 & 240 \\
\hline 2919 & 1.025 & 0.045 & 0.959 & 1,052 & 7751 & 1.653 & 0.140 & 0.951 & 280 \\
\hline 2922 & 0.591 & 0.028 & 0.927 & 898 & 7752 & 1.512 & 0.087 & 0.952 & 601 \\
\hline 2924 & 0.789 & 0.032 & 0.916 & 1,232 & 7754 & 1.086 & 0.127 & 0.831 & 146 \\
\hline 2925 & 1.160 & 0.061 & 0.924 & 718 & 7757 & 1.995 & 0.140 & 0.968 & 408 \\
\hline 2926 & 1.094 & 0.076 & 0.888 & 419 & 7758 & 2.120 & 0.137 & 0.958 & 476 \\
\hline 2927 & 0.857 & 0.051 & 0.949 & 575 & 7781 & 1.598 & 0.086 & 0.988 & 686 \\
\hline 2929 & 0.909 & 0.038 & 0.957 & 1,166 & 7782 & 1.491 & 0.110 & 0.965 & 368 \\
\hline 3221 & 0.915 & 0.071 & 0.863 & 334 & 7783 & 2.024 & 0.157 & 0.948 & 334 \\
\hline 3224 & 1.092 & 0.106 & 0.914 & 211 & 7784 & 1.226 & 0.113 & 0.903 & 234 \\
\hline 3231 & 0.774 & 0.072 & 0.954 & 229 & 7788 & 1.675 & 0.118 & 0.984 & 403 \\
\hline 3232 & 1.051 & 0.084 & 0.966 & 314 & 7821 & 1.927 & 0.159 & 0.914 & 295 \\
\hline 3341 & 1.070 & 0.048 & 0.951 & 995 & 7822 & 1.360 & 0.128 & 0.976 & 227 \\
\hline 3343 & 0.956 & 0.044 & 0.930 & 956 & 7831 & 1.430 & 0.093 & 0.974 & 470 \\
\hline 3344 & 0.964 & 0.043 & 0.931 & 1,018 & 7849 & 3.282 & 0.278 & 0.895 & 278 \\
\hline 3345 & 1.215 & 0.063 & 0.977 & 756 & 7852 & 1.481 & 0.117 & 0.955 & 323 \\
\hline 3351 & 1.181 & 0.092 & 0.941 & 328 & 7912 & 0.971 & 0.185 & 0.949 & 55 \\
\hline 3352 & 0.903 & 0.059 & 0.961 & 471 & 7925 & 1.111 & 0.229 & 0.920 & 47 \\
\hline 3353 & 0.966 & 0.067 & 0.985 & 419 & 7928 & 1.149 & 0.152 & 0.985 & 114 \\
\hline 3354 & 0.990 & 0.062 & 0.989 & 516 & 7932 & 1.141 & 0.147 & 0.917 & 121 \\
\hline 3359 & 0.698 & 0.056 & 0.946 & 306 & 8121 & 2.148 & 0.161 & 0.863 & 357 \\
\hline 4111 & 0.628 & 0.042 & 0.917 & 444 & 8122 & 1.312 & 0.067 & 0.990 & 775 \\
\hline
\end{tabular}




\begin{tabular}{|c|c|c|c|c|c|c|c|c|c|}
\hline \multirow{2}{*}{$\begin{array}{l}\text { Table B3 } \\
\text { sector }\end{array}$} & \multicolumn{4}{|c|}{ 4-digit trade flows } & \multirow[b]{2}{*}{ sector } & \multicolumn{4}{|c|}{ 4-digit trade flows } \\
\hline & estimate & st error & fit & \# obs & & estimate & st error & fit & \# obs \\
\hline 4113 & 1.083 & 0.086 & 0.921 & 317 & 8124 & 1.798 & 0.113 & 0.949 & 509 \\
\hline 4232 & 0.846 & 0.063 & 0.966 & 366 & 8212 & 1.444 & 0.143 & 0.980 & 203 \\
\hline 4239 & 1.502 & 0.118 & 0.935 & 322 & 8219 & 1.430 & 0.130 & 0.982 & 243 \\
\hline 4241 & 0.549 & 0.058 & 0.860 & 180 & 8421 & 1.074 & 0.047 & 0.938 & 1,040 \\
\hline 4243 & 0.542 & 0.037 & 0.828 & 422 & 8422 & 0.969 & 0.044 & 0.953 & 950 \\
\hline 4249 & 0.771 & 0.036 & 0.905 & 931 & 8423 & 0.943 & 0.040 & 0.905 & 1,124 \\
\hline 4313 & 1.187 & 0.083 & 0.962 & 407 & 8429 & 1.111 & 0.047 & 0.922 & 1,123 \\
\hline 4314 & 0.677 & 0.036 & 0.918 & 689 & 8431 & 1.113 & 0.050 & 0.922 & 1,005 \\
\hline 5111 & 1.668 & 0.247 & 0.937 & 91 & 8432 & 1.092 & 0.050 & 0.955 & 964 \\
\hline 5112 & 1.668 & 0.246 & 0.938 & 92 & 8433 & 1.061 & 0.047 & 0.960 & 1,022 \\
\hline 5119 & 1.668 & 0.247 & 0.937 & 91 & 8434 & 1.078 & 0.047 & 0.915 & 1,034 \\
\hline 5121 & 1.407 & 0.084 & 0.991 & 559 & 8441 & 0.939 & 0.042 & 0.917 & 1,017 \\
\hline 5123 & 1.600 & 0.125 & 0.960 & 326 & 8442 & 0.942 & 0.044 & 0.895 & 911 \\
\hline 5157 & 0.696 & 0.072 & 0.984 & 188 & 8451 & 1.127 & 0.053 & 0.960 & 910 \\
\hline 5161 & 1.585 & 0.143 & 0.982 & 246 & 8452 & 1.112 & 0.054 & 0.926 & 839 \\
\hline 5162 & 1.683 & 0.118 & 0.974 & 408 & 8459 & 1.160 & 0.053 & 0.907 & 958 \\
\hline 5169 & 0.960 & 0.065 & 0.980 & 437 & 8461 & 1.046 & 0.046 & 0.925 & 1,050 \\
\hline 5221 & 1.593 & 0.099 & 0.951 & 516 & 8463 & 0.625 & 0.046 & 0.963 & 371 \\
\hline 5222 & 0.718 & 0.046 & 0.937 & 482 & 8465 & 0.841 & 0.043 & 0.962 & 774 \\
\hline 5224 & 1.533 & 0.113 & 0.988 & 365 & 8471 & 1.180 & 0.059 & 0.960 & 794 \\
\hline 5225 & 0.804 & 0.044 & 0.962 & 679 & 8472 & 1.128 & 0.055 & 0.944 & 832 \\
\hline 5231 & 1.530 & 0.086 & 0.972 & 626 & 8481 & 0.953 & 0.051 & 0.920 & 710 \\
\hline 5239 & 1.082 & 0.071 & 0.962 & 465 & 8482 & 1.148 & 0.075 & 0.934 & 473 \\
\hline 5331 & 1.651 & 0.106 & 0.974 & 487 & 8483 & 0.878 & 0.050 & 0.944 & 626 \\
\hline 5334 & 1.905 & 0.102 & 0.973 & 704 & 8484 & 1.265 & 0.072 & 0.934 & 616 \\
\hline 5411 & 1.185 & 0.101 & 0.962 & 277 & 8741 & 1.293 & 0.078 & 0.987 & 556 \\
\hline 5413 & 1.398 & 0.091 & 0.983 & 475 & 8745 & 1.611 & 0.120 & 0.975 & 360 \\
\hline 5414 & 1.037 & 0.063 & 0.947 & 536 & 8748 & 2.058 & 0.164 & 0.982 & 316 \\
\hline 5415 & 0.916 & 0.068 & 0.969 & 365 & 8749 & 1.637 & 0.127 & 0.985 & 335 \\
\hline 5416 & 1.009 & 0.068 & 0.981 & 441 & 8811 & 1.449 & 0.127 & 0.895 & 260 \\
\hline 5417 & 1.466 & 0.079 & 0.977 & 695 & 8813 & 1.619 & 0.170 & 0.954 & 181 \\
\hline 5419 & 1.702 & 0.103 & 0.989 & 549 & 8822 & 2.524 & 0.210 & 0.966 & 288 \\
\hline 5513 & 0.826 & 0.039 & 0.980 & 912 & 8841 & 1.705 & 0.152 & 0.925 & 252 \\
\hline 5542 & 1.298 & 0.063 & 0.977 & 836 & 8842 & 1.070 & 0.078 & 0.968 & 376 \\
\hline 5543 & 1.386 & 0.080 & 0.981 & 598 & 8851 & 0.863 & 0.071 & 0.856 & 292 \\
\hline 5621 & 0.967 & 0.050 & 0.965 & 740 & 8852 & 1.421 & 0.108 & 0.897 & 347 \\
\hline 5622 & 0.628 & 0.041 & 0.931 & 473 & 8921 & 1.532 & 0.090 & 0.987 & 573 \\
\hline 5623 & 0.905 & 0.086 & 0.933 & 224 & 8922 & 2.082 & 0.134 & 0.949 & 486 \\
\hline 5629 & 1.119 & 0.066 & 0.953 & 575 & 8925 & 0.808 & 0.079 & 0.920 & 208 \\
\hline 5921 & 1.172 & 0.076 & 0.940 & 480 & 8928 & 1.248 & 0.069 & 0.969 & 649 \\
\hline 5922 & 1.256 & 0.076 & 0.971 & 546 & 8931 & 1.748 & 0.087 & 0.975 & 806 \\
\hline 5981 & 0.931 & 0.063 & 0.936 & 443 & 8939 & 1.984 & 0.114 & 0.982 & 602 \\
\hline 5989 & 2.307 & 0.172 & 0.972 & 359 & 8942 & 1.156 & 0.083 & 0.931 & 388 \\
\hline 6113 & 0.790 & 0.102 & 0.910 & 120 & 8946 & 1.366 & 0.092 & 0.975 & 439 \\
\hline
\end{tabular}




\begin{tabular}{l|cccr|c|cccr} 
Table B3 & \multicolumn{5}{|c|}{ 4-digit trade flows } & \multicolumn{5}{|c}{ 4-digit trade flows } \\
sector & estimate & st error & fit & \# obs & sector & estimate & st error & fit & \# obs \\
\hline 6114 & 0.828 & 0.077 & 0.961 & 232 & 8947 & 0.919 & 0.060 & 0.959 & 464 \\
6282 & 1.917 & 0.121 & 0.973 & 505 & 8981 & 1.562 & 0.123 & 0.957 & 325 \\
6289 & 1.102 & 0.077 & 0.925 & 415 & 8982 & 1.761 & 0.154 & 0.953 & 263 \\
6341 & 0.802 & 0.037 & 0.939 & 925 & 8983 & 1.631 & 0.120 & 0.991 & 371 \\
6342 & 1.000 & 0.054 & 0.942 & 697 & 8991 & 0.849 & 0.049 & 0.965 & 591 \\
6343 & 1.255 & 0.075 & 0.959 & 566 & 8996 & 1.320 & 0.110 & 0.903 & 290 \\
6351 & 1.067 & 0.057 & 0.939 & 711 & 8997 & 1.156 & 0.054 & 0.950 & 920 \\
6353 & 1.199 & 0.062 & 0.932 & 746 & 8998 & 1.798 & 0.109 & 0.970 & 547 \\
6359 & 1.210 & 0.056 & 0.980 & 921 & 8999 & 0.966 & 0.070 & 0.891 & 386 \\
6411 & 1.085 & 0.107 & 0.751 & 207 & 9999 & 0.800 & 0.040 & 0.803 & 783 \\
6412 & 1.079 & 0.076 & 0.932 & 400 & all & 0.869 & 0.003 & 0.991 & 221,430
\end{tabular}

